\title{
The proteomic response of sea squirts (genus Ciona) to acute heat stress: A global perspective on the thermal stability of proteins
}

\author{
Loredana Serafini , Jay B. Hann , Dietmar Kültz , Lars Tomanek
}

\begin{abstract}
A B S T R A C T
Congeners belonging to the genus Ciona have disparate distributions limited by temperature. Ciona intestinalis is more widespread with a cosmopolitan distribution ranging from tropical to sub-arctic zones, while Ciona savignyi is limited to temperate-latitudes of the northern Pacific Ocean. To compare the heat stress response between congeners, we quantified changes in protein expression using proteomics. Animals were exposed to $22^{\circ} \mathrm{C}, 25^{\circ} \mathrm{C}$, and $28^{\circ} \mathrm{C}$ for $6 \mathrm{~h}$, then recovered at a control temperature $\left(13^{\circ} \mathrm{C}\right)$ for $16 \mathrm{~h}$ (high heat stress experiment). In a second experiment we exposed animals to lower levels of heat stress at $18{ }^{\circ} \mathrm{C}, 20^{\circ} \mathrm{C}$, and $23^{\circ} \mathrm{C}$, with a $16^{\circ} \mathrm{C}$ control. A quantitative analysis, using 2D gel electrophoresis and MALDI-TOF/TOF mass spectrometry (with a 69\% and 93\% identification rate for Ciona intestinalis and Ciona savignyi, respectively), showed changes in a number of protein functional groups, including molecular chaperones, extracellular matrix proteins, calcium-binding proteins, cytoskeletal proteins and proteins involved in energy metabolism. Our results indicate that $C$. intestinalis maintains higher constitutive levels of molecular chaperones than C. savignyi, suggesting that it is prepared to respond faster to thermal stress. Systematic discrepancies between estimated versus predicted molecular masses of identified proteins differed between protein families and were more pronounced under high heat conditions, suggesting that thermal sensitivities are lower for cytoskeletal proteins and ATPsynthase than for any other protein group represented on $2 \mathrm{D}$ gels.
\end{abstract}

\section{Introduction}

Temperature has a ubiquitous effect on the rate of physiological reactions and the stability of macromolecular structures and thus plays an important role in limiting the geographic distribution ranges of organisms (Hochachka and Somero, 2002; Tomanek, 2008, 2010; Pörtner, 2010; Somero, 2010). Recent increases in global temperature averages and extremes due to climate change, along with further increases forecasted by climate models, highlight the importance of studying the thermal stress response in order to predict the effects of increased thermal stress on species distribution and, ultimately, survival (IPCC, 2007).

A number of studies have elucidated the cellular mechanisms involved in responding to thermal stress and the evolutionarily conserved heat shock response (HSR) including the role of molecular chaperones in protecting proteins from denaturation, repairing misfolded proteins, and facilitating the degradation of irreversibly damaged proteins (for review see Hochachka and Somero, 2002; Kültz, 2005; Tomanek, 2008). To gain a comprehensive understanding of these mo- lecular mechanisms, many transcriptomic studies have utilized a global approach to simultaneously characterize changes in the expression of thousands of mRNA transcripts, corresponding to thousands of genes, in response to environmental stress (Gracey and Cossins, 2003; Podrabsky and Somero, 2004; Gracey et al., 2008; Stillman and Tagmount, 2009; Lockwood et al., 2010). This approach has lead to the discovery of many physiological processes that serve as novel indicators for acute thermal stress (for review see Tomanek, 2010). However, many studies, with a few exceptions (Buckley et al., 2006), have not verified that the changes in mRNA transcripts are translated into functional proteins, which represent the molecular phenotype and are a better measure of cellular function (Feder and Walser, 2005).

Recent progress in the field of proteomics, an experimental approach that allows for the simultaneous characterization of the abundance of hundreds of proteins, has made it possible to identify a great number of novel proteins that show significant expression changes in response to a variety of environmental stresses (Tomanek, 2011). These changes in protein expression (or abundance) can be the result of protein synthesis, degradation, or post-translational modifications, and the term "expression" is used broadly to refer to all three events. Surprisingly, there are only a small number of proteomic studies that examine cellular responses to thermal stress. Although several studies used 2D gel electrophoresis to characterize the heat 
shock responses of different species (Sanders et al., 1991; White et al., 1994; Kültz, 1996; Garbuz et al., 2003; Tomanek, 2005), to our knowledge, only two other studies utilized mass spectrometry-based proteomics to compare the responses to acute and chronic thermal stress (Ibarz et al., 2010; Tomanek and Zuzow, 2010).

In this study, we chose to examine the HSR of the closely related sea squirt congeners, $C$. intestinalis and $C$. savignyi. Ascidian tunicates belonging to the genus Ciona are sessile and solitary marine invertebrates that reproduce by broadcast spawning and can thrive on both natural substrates, such as eelgrass beds, and artificial substances, like ship hulls (Millar, 1953, 1971; Byrd and Lambert, 2000; Berná et al., 2009). Their opportunistic nature has allowed them to take advantage of anthropogenic means of dispersal, mostly by hull-fouling, which has contributed to their classification as invasive species (Ritter and Forsyth, 1917; Svane and Havenhand, 1993; Hewitt et al., 2002; McDonald, 2004; Blum et al., 2007). Their fully sequenced and annotated genomes, and key evolutionary position, make these modern urochordates an ideal study system for comparative physiological studies, as well as for clarifying chordate phylogeny and the mechanisms behind vertebrate development and evolution (Dehal et al., 2002; Satoh et al., 2003; Vinson et al., 2005; Nydam and Harrison, 2007; Berná et al., 2009).

Although these two sister species share many aspects of their natural history and ecology, their distribution ranges differ. C. intestinalis has a nearly worldwide coastal distribution, while $C$. savignyi is a Pacific species geographically restricted to Japan and the western coast of North America, spanning from British Columbia to the southern tip of California (Lambert, 2003; Therriault and Herborg, 2008; Berná et al., 2009). The relative phylogenetic proximity of the two Ciona congeners, in addition to differences in their distribution ranges, provides a species comparison that emphasizes the molecular adaptations responsible for variation in the cellular response to heat stress.

Several studies define the thermal tolerance ranges of the two Ciona species; however, no direct species comparisons within the same life stage exist to date, so very little is known concerning their relative thermal tolerances (Dybern, 1965; Marin et al., 1987; Nomaguchi et al., 1997; Therriault and Herborg, 2008). C. savignyi embryos have optimal cleavage temperatures ranging from $10^{\circ} \mathrm{C}$ to $27^{\circ} \mathrm{C}$, depending on the season during which they are spawned (Nomaguchi et al., 1997). Juvenile C. intestinalis show elevated levels of Hsp70 mRNA at $28^{\circ} \mathrm{C}$ and $33^{\circ} \mathrm{C}$ (Fujikawa et al., 2010). For adult C. intestinalis, temperature tolerance has been shown to range from $-1{ }^{\circ} \mathrm{C}$ to an upper threshold of $30^{\circ} \mathrm{C}$; however, adult mortality increases at temperatures below $10^{\circ} \mathrm{C}$, so $10^{\circ} \mathrm{C}$ to $30^{\circ} \mathrm{C}$ is a more realistic thermal range (Dybern, 1965 ; Therriault and Herborg, 2008). In addition, increased thermal stress, as indicated by decreased rate of algal filtration, has been observed at temperatures above $21^{\circ} \mathrm{C}$ in C. intestinalis (Petersen and Riisgård, 1992; Therriault and Herborg, 2008). Thus, the upper limit for long-term survival is certainly lower than $30^{\circ} \mathrm{C}$.

The goal of the present study was to use the discovery approach of proteomics to characterize the acute thermal stress responses of the two Ciona congeners. We focus on identifying species-specific differences in their thermal responses, which may underlie variations in thermal tolerance that lead to their distinct distribution ranges. Using existing estimates of ecological thermal tolerance range as a guide, two separate experiments were conducted to evaluate the proteomic responses of the Ciona congeners when exposed to extreme and moderate heat stress. The high heat stress (HHS) experiment included treatment temperatures ranging from $22^{\circ} \mathrm{C}$ to $28^{\circ} \mathrm{C}\left(13^{\circ} \mathrm{C}\right.$ control), while exposure temperatures in the low heat stress (LHS) experiment ranged from $18{ }^{\circ} \mathrm{C}$ to $23^{\circ} \mathrm{C}\left(16^{\circ} \mathrm{C}\right.$ control $)$. Using two-dimensional gel electrophoresis (2D GE) and tandem mass spectrometry (MS/MS), we were able to identify the majority of the proteins that showed significant changes in expression, either due to protein synthesis, degradation, or post-translational modifications, in response to low and high levels of heat stress.
In comparing significantly changing proteins, specifically molecular chaperones, between species, we were able to identify speciesspecific differences in the molecular responses to thermal stress, which may contribute to setting the thermal tolerance limits that result in the observed disparate distribution ranges. We also found that some of the proteins identified in the heat stress experiments showed discrepancies in estimated (gel-based) versus predicted (database-driven) molecular mass, more so in the high heat stress experiment. After accounting for proteolytic activity, these discrepancies were dependent on species and level of thermal stress and specific to certain functional groups of proteins, and thus may provide a global perspective of the differing thermal sensitivities of various cellular pathways.

\section{Materials and methods}

\subsection{Animal collection and maintenance}

C. intestinalis (Linnaeus, 1767) and C. savignyi (Herdman, 1882) were collected subtidally from the Yacht Harbor in Santa Barbara, California, USA $\left(34^{\circ} 24^{\prime} 13^{\prime \prime} \mathrm{N}, 119^{\circ} 41^{\prime} 31^{\prime \prime} \mathrm{W}\right)$. Species were differentiated from one another based on the color of the pigment spot present at the tip of the sperm duct, which is orange in C. intestinalis and white in C. savignyi (Hoshino and Tokioka, 1967). Animals were transported back to San Luis Obispo, CA, USA in insulated coolers and kept overnight at a control temperature $\left(13^{\circ} \mathrm{C}\right.$ for the high heat stress [HHS] experiment, and $16{ }^{\circ} \mathrm{C}$ for the low heat stress [LHS] experiment) in recirculating seawater tanks. The different control temperatures used in each experiment reflect the average water temperatures at the collection site during the season in which each experiment was run, late summer for the LHS experiment, and early spring for the HHS experiment (Fig. S1).

\subsection{Experimental design}

\subsubsection{High heat stress experiment}

C. intestinalis and C. savignyi were placed in a temperature-controlled ice-chest with circulating seawater and aeration. The temperature was increased by $6{ }^{\circ} \mathrm{Ch}^{-1}$ from $13^{\circ} \mathrm{C}$ to $22^{\circ} \mathrm{C}, 25^{\circ} \mathrm{C}$ or $28^{\circ} \mathrm{C}(\mathrm{n}=5$ for all groups, with the following exceptions: $\mathrm{n}=4$ for $\mathrm{C}$. savignyi $13^{\circ} \mathrm{C}$ and $25^{\circ} \mathrm{C}$ ). Sea squirts were kept at these temperatures for a $6 \mathrm{~h}$ incubation and subsequently brought back to $13^{\circ} \mathrm{C}$ for a $16 \mathrm{~h}$ recovery period (Fig. S2). Immediately after recovery, individuals were pooled into samples to obtain sufficient amounts of protein ( 2 C. intestinalis individuals per sample and $3 C$. savignyi per sample), and samples were flash-frozen in liquid nitrogen and stored at $-80^{\circ} \mathrm{C}$.

\subsubsection{Low heat stress experiment}

The LHS experiment used the same basic design as the HHS experiment, but with different temperatures. The control temperature was $16{ }^{\circ} \mathrm{C}$, and the three treatment temperatures were $18^{\circ} \mathrm{C}, 20^{\circ} \mathrm{C}$, and $23^{\circ} \mathrm{C}$. As in the HHS experiment, the rate of temperature increase was $6^{\circ} \mathrm{C} \mathrm{h}^{-1}$, and sea squirts remained at their target temperature for a $6 \mathrm{~h}$ incubation, and were cooled back down to $16^{\circ} \mathrm{C}$ for a $16 \mathrm{~h}$ recovery period ( $\mathrm{n}=5$ for all groups; Fig. $\mathrm{S} 2$ ). Individuals were pooled into samples consisting of 2 individuals for $C$. intestinalis and 3 individuals for $C$. savignyi, and samples were flash-frozen in liquid nitrogen immediately following recovery and kept at $-80^{\circ} \mathrm{C}$.

\subsubsection{Protease inhibitor experiment}

To determine whether serine, cysteine, metallo-, and aspartic protease activity affects sample preparation, additional $C$. intestinalis and C. savignyi were collected from the Santa Barbara Yacht Harbor in September 2010 and were immediately flash-frozen in liquid nitrogen. For each species, half of the samples were processed with our standard homogenization buffer (see Section 2.3), while the other half 
were processed with homogenization buffer containing inhibitors for aspartic, serine, cysteine, and metallo-proteases (see Section 2.3; $\mathrm{n}=5$ for both species).

\subsection{Dissection and homogenization}

Frozen samples were thawed and the outer tunic membrane was dissected off of each individual. The contents of the stomach and intestine were removed, and the remaining tissues (all internal organs and structures) were pooled into ice-cold ground-glass homogenizers. The tissue was lysed in a ratio of 1:2 of tissue to homogenization buffer ( $7 \mathrm{~mol} \mathrm{~L}^{-1}$ urea, $2 \mathrm{~mol} \mathrm{~L}^{-1}$ thiourea, 1\% ASB (amidosulfobetaine)-14, $40 \mathrm{mmol} \mathrm{L}^{-1}$ Tris-base, $0.5 \%$ immobilized $\mathrm{pH} 4-7$ gradient (IPG) buffer (GE Healthcare, Piscataway, NJ, USA) and $40 \mathrm{mmol} \mathrm{L}^{-1}$ dithiothreitol).

For the protease inhibitor experiment samples, one tablet of complete Mini protease inhibitor cocktail was added for every $10 \mathrm{~mL}$ of homogenization buffer (Roche, Mannheim, Germany). This cocktail enabled inhibition of serine, cysteine, and metallo-proteases. Pepstatin, an inhibitor of aspartic proteases, was also added to the homogenization buffer $\left(0.7 \mu \mathrm{g} \mathrm{mL}^{-1}\right)$ prior to tissue lysis.

The homogenate was subsequently centrifuged at room temperature for $30 \mathrm{~min}$ at $16,100 \mathrm{~g}$ and the supernatant was used for further processing. Proteins of the supernatant were precipitated by adding four volumes of ice-cold $10 \%$ trichloro-acetic acid in acetone and incubating the solution at $-20^{\circ} \mathrm{C}$ overnight. After a 15 min centrifugation at $4{ }^{\circ} \mathrm{C}$ and $18,000 \mathrm{~g}$, the supernatant was discarded and the remaining pellet was washed with ice-cold acetone, and centrifuged again before being re-suspended in rehydration buffer $\left(7 \mathrm{~mol} \mathrm{~L}^{-1}\right.$ urea, $2 \mathrm{~mol} \mathrm{~L}^{-1}$ thiourea, $3.25 \mathrm{mmol} \mathrm{L}^{-1}$ CHAPS (cholamidopropul-dimethylammoniopropanesulfonic acid), 2\% NP-40 (nonyl phenoxylpolyethoxylethanol40), $0.002 \%$ bromophenol blue, $0.5 \%$ IPG buffer and $100 \mathrm{mmol} \mathrm{L}^{-1}$ dithioerythritol) through vortexing. The protein concentration was determined with the 2D Quant kit (GE Healthcare), according to the manufacturer's instructions.

\subsection{Two-dimensional gel electrophoresis}

Proteins $(800 \mu \mathrm{g})$ were loaded onto immobilized $\mathrm{pH}$ gradient strips ( $\mathrm{pH} 4-7,24 \mathrm{~cm}$; BioRad, Hercules, CA, USA) for separation according to their isoelectric point ( $\mathrm{pI}$ ). We started the isoelectric focusing protocol with $12 \mathrm{~h}$ of active rehydration ( $50 \mathrm{~V}$ ), using an isoelectric focusing cell (BioRad). The following protocol was used for the remainder of the run (all voltage changes occurred in rapid mode): $250 \mathrm{~V}$ for $15 \mathrm{~min}$, $10,000 \mathrm{~V}$ for $3 \mathrm{~h}, 10,000 \mathrm{~V}$ for $80,000 \mathrm{~V}$ h, and a $500 \mathrm{~V}$ hold step. Once removed from the IEF cell, the strips were frozen and stored at $-80^{\circ} \mathrm{C}$.

Frozen strips were thawed and incubated in equilibration buffer (375 $\mathrm{mmol} \mathrm{L}^{-1}$ Tris-base, $6 \mathrm{~mol} \mathrm{~L}^{-1}$ urea, 30\% glycerol, 2\% SDS (sodium dodecyl sulfate) and $0.0002 \%$ bromophenol blue) for $15 \mathrm{~min}$, first with $65 \mathrm{mmol} \mathrm{L}^{-1}$ dithiothreitol and then, second, with $135 \mathrm{mmol} \mathrm{L}^{-1}$ iodoacetamide. IPG strips were placed on top of an $11.8 \%$ polyacrylamide gel with a $0.8 \%$ agarose solution containing Laemmli SDS electrophoresis (or running) buffer $\left(25 \mathrm{mmol} \mathrm{L}^{-1}\right.$ Trisbase, $192 \mathrm{mmol} \mathrm{L}^{-1}$ glycine, $0.1 \% \mathrm{SDS}$ ). For the HHS experiment, $24 \mathrm{~cm}$ IPG strips were run on large-format gels, $26 \times 20 \mathrm{~cm}$, at $30 \mathrm{~W}$ for $30 \mathrm{~min}$, and $100 \mathrm{~W}$ for $4 \mathrm{~h}$ (Ettan DALTsix; GE Healthcare). For the LHS experiment, large-format gels, $25.6 \times 23.0 \mathrm{~cm}$, were run at $50 \mathrm{~V}$ for $30 \mathrm{~min}$, then $200 \mathrm{~V}$ for $5.5 \mathrm{~h}$ (Protean Plus Dodeca Cell; BioRad). In both cases, recirculating water baths set to $12{ }^{\circ} \mathrm{C}$ were used to keep running buffer cool. Gels were subsequently stained with colloidal Coomassie Blue (G-250) overnight and destained by washing repeatedly with Milli-Q water for $48 \mathrm{~h}$. The resulting gel images were scanned with an Epson 1280 transparency scanner (Epson, Long Beach, CA, USA).

For the protease inhibitor experiment, the same overall protocol was followed, with a few minor deviations. A less concentrated protein solution $(400 \mu \mathrm{g})$ was loaded onto smaller immobilized $\mathrm{pH}$

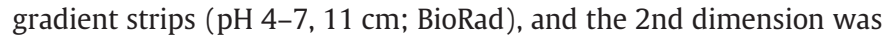
run using small-format gels, $13.3 \times 8.7 \mathrm{~cm}$, that ran at $200 \mathrm{~V}$ for $50 \mathrm{~min}$ (Criterion Dodeca Cell; BioRad). The buffers used were the same as those described for the HHS and LHS experiments.

\subsection{Gel image analysis}

Digitized images of two-dimensional gels were analyzed using Delta2D (version 4.0; Decodon, Greifswald, Germany). We used the group warping strategy to connect gel images through match vectors. All images within a species were fused into a composite image (also known as a proteome map), which represents average volumes for each spot (Fig. 1). Spot boundaries were detected within the proteome map and transferred back to all gel images using match vectors. After background subtraction, protein spot volumes were normalized against total spot volume of all proteins in a gel image (for detailed review of image analysis protocols, see Berth et al., 2007).

\subsection{Mass spectrometry}

Proteins that showed changes in expression in response to treatment were excised from gels using a tissue puncher (Beecher Instruments, Sun Prairie, WI, USA). Gel plugs were destained twice with $25 \mathrm{mmol} \mathrm{L}^{-1}$ ammonium bicarbonate in 50\% acetonitrile, dehydrated with $100 \%$ acetonitrile and digested with $11 \mathrm{ng} \mu \mathrm{L}^{-1}$ trypsin (Promega, Madison, WI, USA) overnight at $37^{\circ} \mathrm{C}$. Digested proteins were extracted using elution buffer (0.1\% TFA (trifluoroacetic acid)/acetonitrile; $2: 1)$ and concentrated using a SpeedVac (Eppendorf, Hauppauge, NY, USA). The elution buffer containing the digested protein was mixed with $5 \mu$ of matrix solution $\left(0.2 \mathrm{mg} \mathrm{mL}^{-1} \alpha\right.$-hydroxycyano cinnamic acid in acetonitrile) and spotted on an Anchorchip ${ }^{\mathrm{TM}}$ target plate (Bruker Daltonics Inc., Billerica, MA, USA). The spotted proteins were washed with a buffer containing $0.1 \%$ TFA in $10 \mathrm{mM}$ ammonium phosphate, and recrystallized using an acetone/ethanol/0.1\% TFA (6:3:1) mixture.

Peptide mass fingerprints (PMFs) were obtained on a matrixassisted laser desorption ionization tandem time-of-flight (MALDITOF-TOF) mass spectrometer (Ultraflex II; Bruker Daltonics Inc., Billerica, MA, USA). We chose a minimum of eight peptides to conduct tandem mass spectrometry in order to obtain information about the $\mathrm{b}$ - and $\mathrm{y}$-ions of the peptide sequence.

To analyze the peptide spectra we used flexAnalysis (version 3.0; Bruker Daltonics Inc.) and applied the TopHat algorithm for baseline subtraction, the Savitzky-Golay analysis for smoothing (with: $0.2 \mathrm{~m} /$ $z$; number of cycles $=1$ ) and the SNAP algorithm to detect peaks (signal-to-noise ratio: 6 for MS and 1.5 for MS/MS). The charge state of the peptides was assumed to be +1 . We used porcine trypsin for internal mass calibration.

To identify proteins we used Mascot (version 2.2; Matrix Science Inc., Boston, MA, USA) and combined PMFs and tandem mass spectra in a search against two databases. One is a genomic database for C. intestinalis that initially contained approximately 8,314,131 entries, representing 19,858 different gene sequences for C. intestinalis (Dehal et al., 2002). The other is a genomic database for $C$. savignyi containing 9,689,492 entries, representing 20,143 gene sequences (Vinson et al., 2005; Small et al., 2007). Oxidation of methionine and carbamidomethylation of cysteine were included as variable modifications. Our search allowed one missed cleavage during trypsin digestion.

For tandem mass spectrometry we used the default setting of a precursor-ion mass tolerance of 0.6 Da recommended for MASCOT. The molecular weight search (MOWSE) score that indicated a significant hit was dependent on the database: scores higher than 29 were significant $(p<0.05)$ in a search in both the $C$. intestinalis and C. savignyi genomic databases. In addition, we only accepted positive identifications that included at least two matched peptides in addition to a MOWSE score above the significance threshold (see Tables S1-S6). 


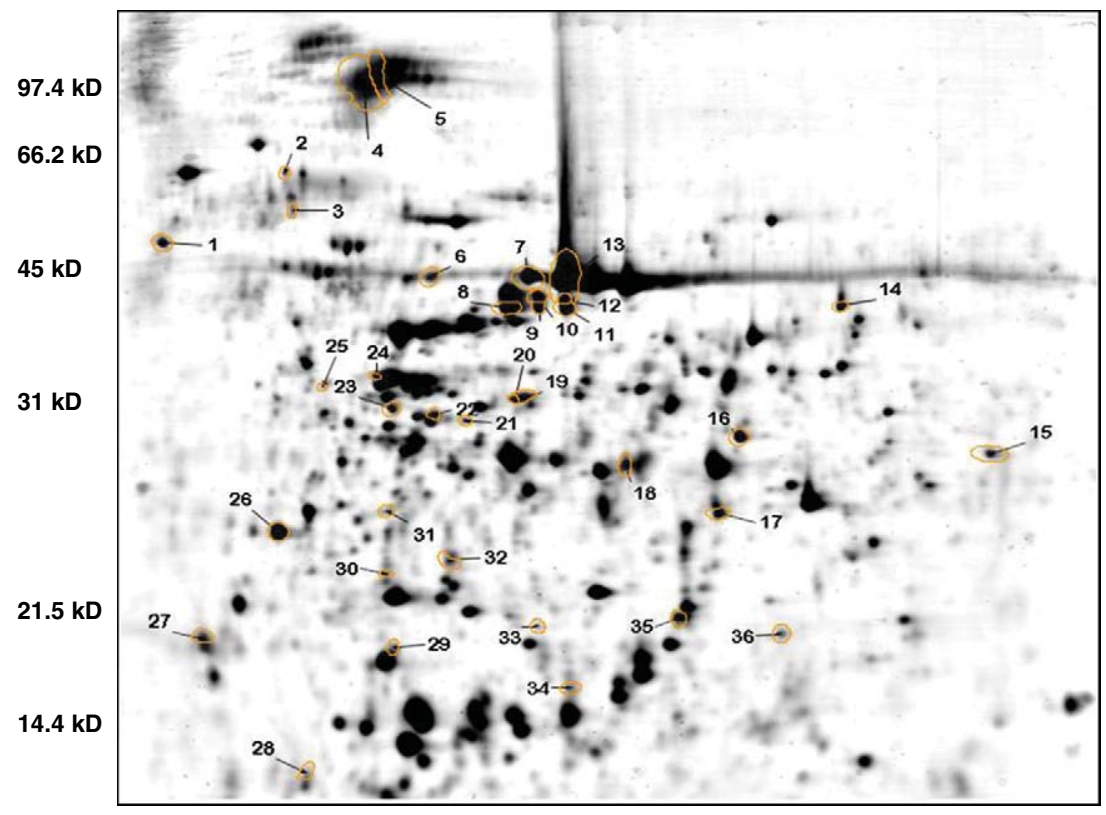

Fig. 1. A composite gel image (or proteome map) depicting the 342 individual protein spots detected in the Ciona intestinalis high heat stress experiment. The proteome map represents the average normalized pixel volumes for each protein spot across all 20 sample gels analyzed. Numbered spots were those that showed changes in abundance in response to acute heat stress treatments (one-way ANOVA, $p<0.05$ ) and were identified using tandem mass spectrometry (for identifications, see Table S1).

\subsection{Statistical analysis}

Normalized spot volumes were analyzed within Delta2D by using an analysis of variance (one-way ANOVA) within each species and with temperature as the main effect. For the one-way ANOVA a null distribution was generated using 1000 permutations to account for the unequal variance and non-normal distributions of the response variables and a $p$-value of 0.05 was used instead of using a multiple-

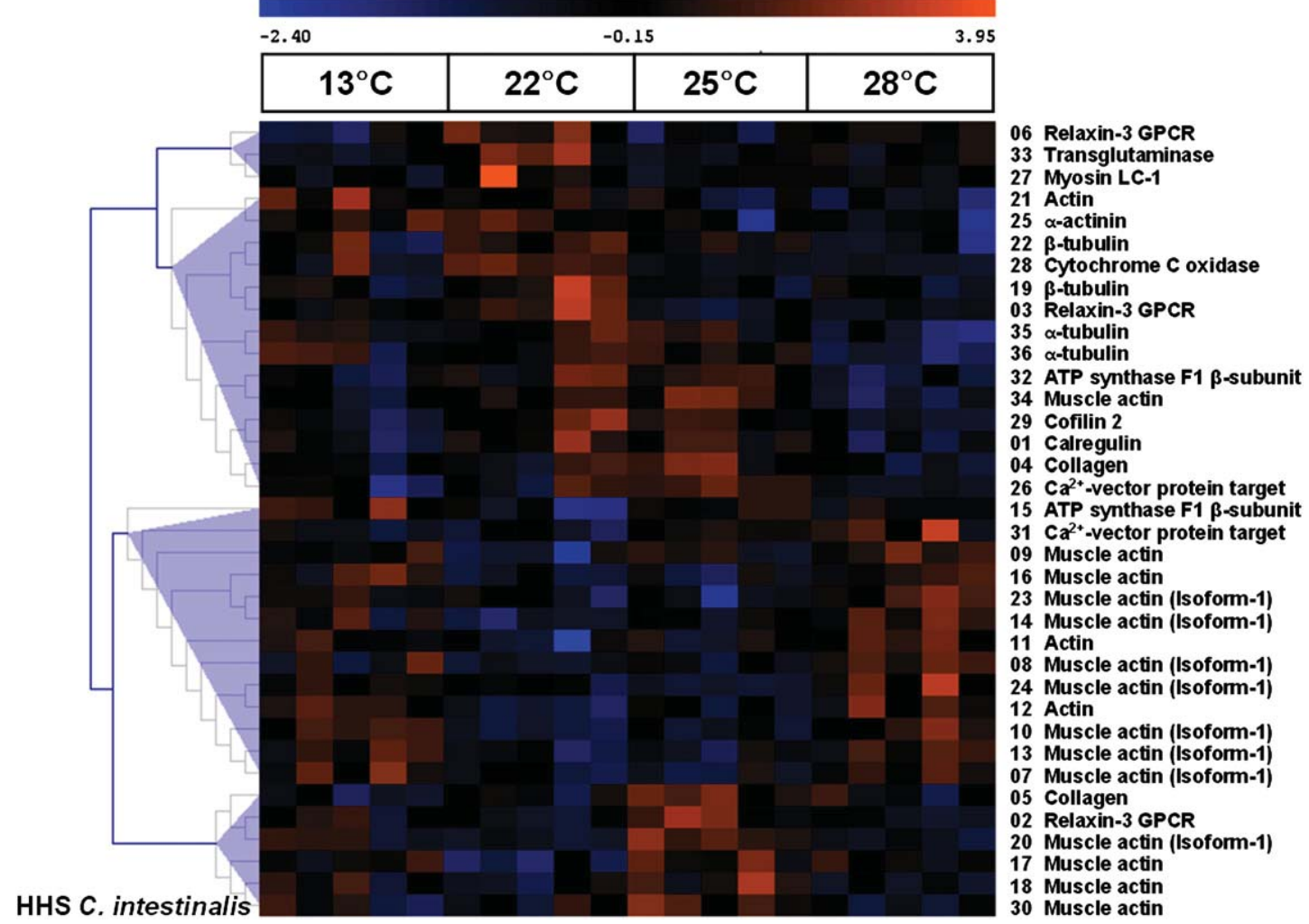

Fig. 2. HHS C. intestinalis- Hierarchical clustering of identified proteins using Pearson's correlation in response to acute high heat stress (HHS). Each square represents a single spot on a single gel, with each row representing a single spot across all of the gels in the experiment, and each column representing all of the spots on a single gel. Blue represents a lower than average standardized spot volume, whereas orange represents a greater than average standardized spot volume. The temperature treatments are labeled along the upper horizontal axis, while the right vertical axis represents the standardized expression patterns of identified proteins. 
comparison correction, which was deemed too strict given that the number of protein spots is much smaller in comparison to microarray experiments. A two-way ANOVA was not possible because a number of gel regions were difficult to match between species, and even for those proteins that overlapped between species it was unclear whether proteins were orthologous or paralogous homologs. Following the one-way ANOVA, post-hoc testing to compare treatments was conducted using Tukey's analysis $(p<0.05)$ in MiniTab (version 16). In our heat maps, we used hierarchical clustering to group proteins based on similarities in their expression patterns. To accomplish this, we used average linking in the statistical tool suite within Delta2D, and used a Pearson's correlation metric.

\section{Results}

\subsection{High heat stress (HHS) experiment}

\subsubsection{C. intestinalis}

All gels from one experiment within C. intestinalis were matched and used to generate a proteome map, which shows the average normalized pixel volume of all proteins detected (Fig. 1, proteome maps from other treatments are shown within Supplementary materials). After spot boundaries were evaluated within this composite map, 342 individual protein spots were detected. Using an ANOVA based on permutations, we determined that 51 protein spots (or $15 \%$ of the total) showed

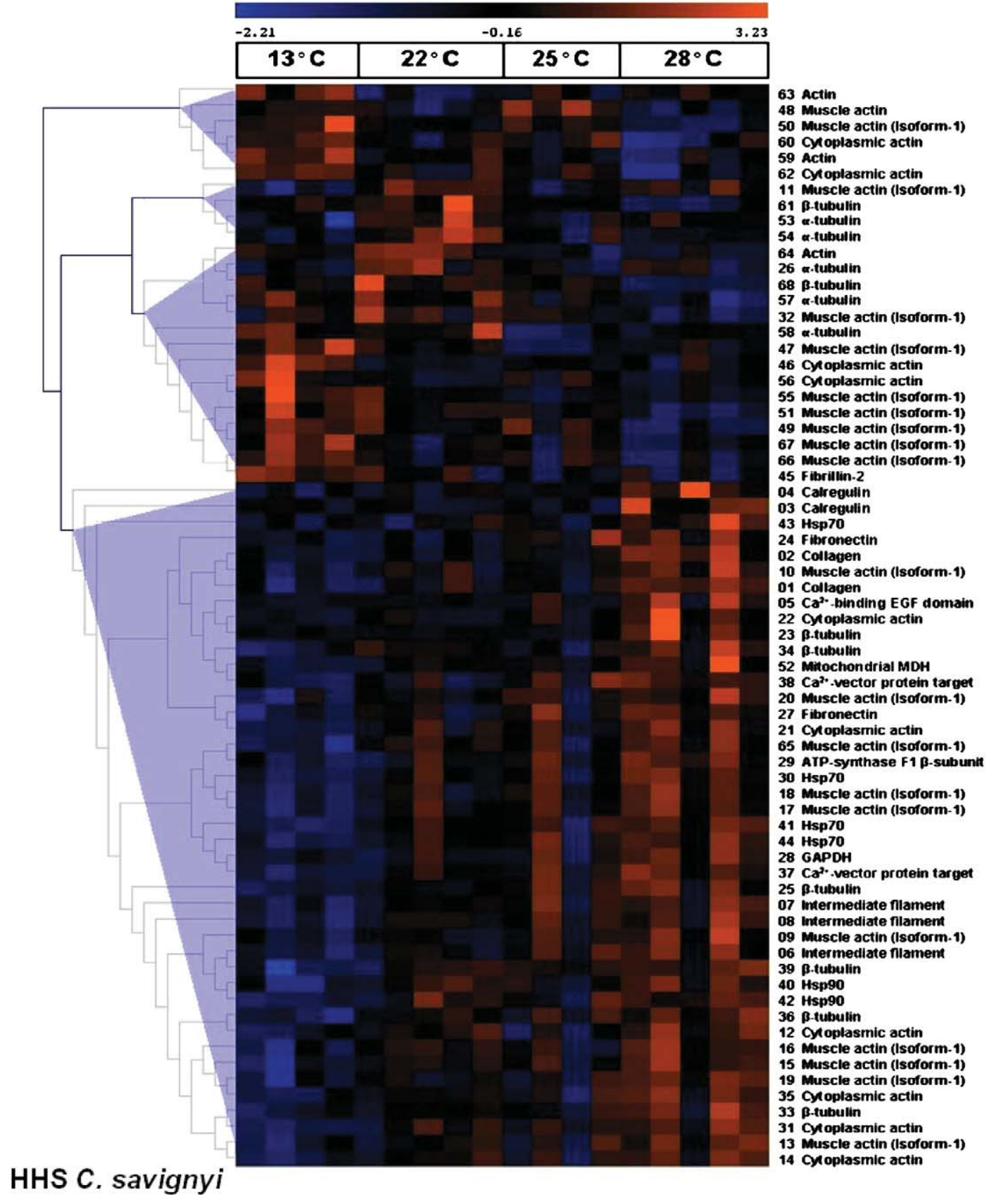

Fig. 3. HHS C. savignyi- Hierarchical clustering of identified proteins using Pearson's correlation in response to acute high heat stress (HHS). Blue represents a lower than average standardized spot volume, whereas orange represents a greater than average standardized spot volume. The temperature treatments are labeled along the upper horizontal axis, while the right vertical axis represents the standardized expression patterns of identified proteins. 


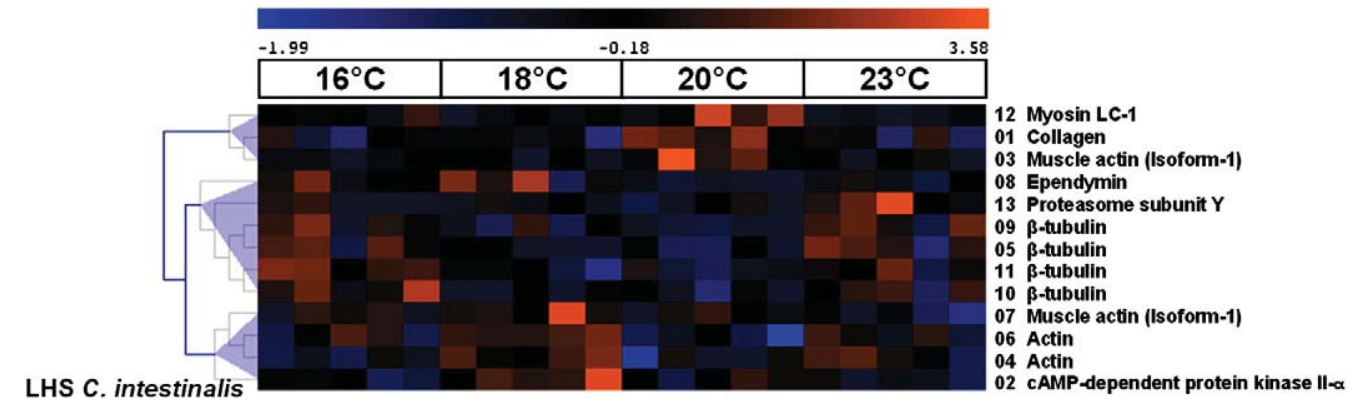

Fig. 4. LHS C. intestinalis- Hierarchical clustering of identified proteins using Pearson's correlation in response to acute low heat stress (LHS). Blue represents a lower than average standardized spot volume, whereas orange represents a greater than average standardized spot volume. The temperature treatments are labeled along the upper horizontal axis, while the right vertical axis represents the standardized expression patterns of identified proteins.

significant changes in their expression across temperature treatment groups $(p<0.05$ ). Of the 51 significant protein spots, 36 spots (or $71 \%$ ) were successfully identified (Fig. 1 and Table S1). To aid in the interpretation of the data, hierarchical clustering was used to generate heat maps which grouped proteins based on similarities in their expression patterns across treatment groups (Fig. 2). Proteins that clustered together often shared the same function, or belonged to the same cellular pathway; therefore, for the sake of brevity, expression patterns will be broken down by functional category and discussed in detail in Section 3.3.

\subsubsection{C. savignyi}

In C. savignyi a total of 403 individual protein spots were detected once spot boundaries were defined within the proteome map (Fig. S3). Using an ANOVA based on permutations, 74 protein spots (or 18\%) showed significant changes in their abundance in response to temperature stress $(p<0.05)$. Of the 74 significantly changing spots, we were able to identify 68 proteins (or $92 \%$ ), which were grouped based on similarities in their expression profiles using hierarchical clustering (Fig. 3 and Table S2, see Section 3.3).

\subsection{Low heat stress (LHS) experiment}

Since the temperatures used in the HHS experiment represent the extreme end of the stress spectrum, in order to assess the effect of mild-to-moderate stress on the Ciona congeners we decided to run another experiment using lower treatment temperatures. The two experiments were run at different times of the year, which is reflected in the distinct control temperatures used for each: $13{ }^{\circ} \mathrm{C}$, a typical water temperature for early spring in Santa Barbara, CA, USA, was used for the HHS experiment, while $16^{\circ} \mathrm{C}$, a common late summer water temperature, was used for the LHS experiment (Fig. S1). Because of the seasonal difference, and the resulting difference in control temperatures, caution must be used when drawing direct comparisons between the two experiments, even though the same methods were used throughout.

\subsubsection{C. intestinalis}

Of the 485 total spots detected in C. intestinalis, 20 proteins (or $4 \%$ ) were found to show significant expression changes across temperature treatments (ANOVA, $p<0.05$ ) of which, we identified $13(65 \%)$ (Fig. S4 and Table S3). Hierarchical clustering separated these proteins into three main clusters that show similar expression patterns in response to treatment (Fig. 4, see Section 3.3).

\subsubsection{C. savignyi}

A permutation-based ANOVA showed that 17 of the 398 proteins detected $(4 \%)$ changed significantly in abundance in response to temperature stress $(p<0.05)$, and all proteins were identified (Fig. S5 and Table S4). Despite similar gene sequence numbers $(20,143$ sequences in the C. savignyi database, and 19,858 sequences in C. intestinalis) we had a higher protein identification rate in $C$. savignyi than in C. intestinalis. The expression patterns of the 17 significant proteins were clustered into three main groups, as shown in the heat map in Fig. 5 (see Section 3.3).

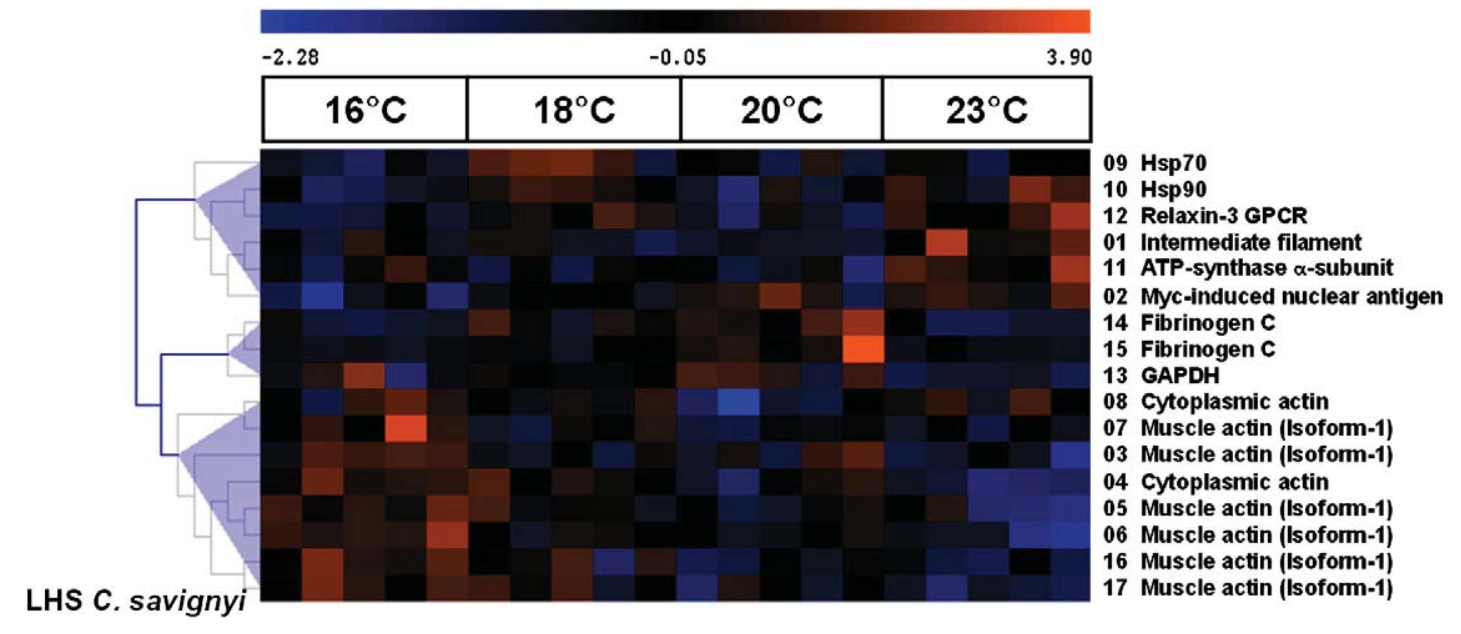

Fig. 5. LHS C. savignyi - Hierarchical clustering of identified proteins using Pearson's correlation in response to acute low heat stress (LHS). Blue represents a lower than average standardized spot volume, whereas orange represents a greater than average standardized spot volume. The temperature treatments are labeled along the upper horizontal axis, while the right vertical axis represents the standardized expression patterns of identified proteins. 


\subsection{Proteins by functional category}

To analyze the expression patterns of so many different proteins between species and heat stress experiments, we organized proteins according to their cellular function to evaluate general expression trends across treatments. To this end, we separated the identified significantly changing proteins into several functional categories, including molecular chaperones, extracellular matrix proteins, calciumbinding proteins, cytoskeletal elements, and proteins involved in energy metabolism.

\subsubsection{Molecular chaperones}

Many molecular chaperones, including heat shock proteins 70 and 90 (Hsp70 and Hsp90), as well as calregulin, an endoplasmic reticulum-resident, calcium-binding chaperone, showed significant changes in their expression across species and experiments (Fig. S6; Nash et al., 1994). In both the high and low heat stress experiments, Hsp70 and Hsp90 only show significant changes in abundance in C. savignyi (Figs. 3 and 5); their expression does not change significantly in C. intestinalis (Figs. 2 and 4). In the high heat stress experiment, C. savignyi up-regulates Hsp expression in the $28^{\circ} \mathrm{C}$ treatment, while in the low heat stress experiment, $\mathrm{Hsp} 70$ is up-regulated at $18{ }^{\circ} \mathrm{C}$ and Hsp90 at $20^{\circ} \mathrm{C}$ (post hocTukey's analysis; $p<0.05$ ).

In addition, we identified one of the Hsp70 isoforms in both species, so we were able to compare heat shock protein levels between species and experiments. As shown in Fig. 6, this particular isoform of Hsp70 only shows significant changes in expression in $C$. savignyi in the high heat stress experiment, where it is up-regulated in the $28{ }^{\circ} \mathrm{C}$ treatment. Thus, baseline levels of this Hsp70 isoform were lowest in HHS C. savignyi, and after up-regulation in the $28{ }^{\circ} \mathrm{C}$ treatment, the amount of protein is comparable to the baseline levels found in
C. intestinalis in both heat stress experiments, as well as the baseline level for $C$. savignyi in the low heat stress experiment.

Calregulin does not show significant changes in expression in the low heat stress experiment; however, in the high heat stress experiment, it is apparent that $C$. intestinalis up-regulates calregulin at $22{ }^{\circ} \mathrm{C}$, while $\mathrm{C}$. savignyi does not show up-regulation of calregulin until the $28{ }^{\circ} \mathrm{C}$ treatment group (Figs. 2-5, S6). This trend of $C$. intestinalis increasing protein abundance at a lower temperature than $C$. savignyi is seen for several other proteins throughout both experiments. We were also able to identify one of the calregulin isoforms in both species, which allowed us to compare calregulin expression across both species and experiments. This isoform of calregulin showed significant expression changes in both species in the HHS experiment, but was not significant in either species in the LHS experiment (Fig. 7). In the HHS experiment, baseline levels of calregulin are higher in C. intestinalis than they are in C. savignyi, and even after up-regulation (which occurs at $22{ }^{\circ} \mathrm{C}$ relative to $28{ }^{\circ} \mathrm{C}$ in $\mathrm{C}$. intestinalis, and $28{ }^{\circ} \mathrm{C}$ relative to $22^{\circ} \mathrm{C}$ and $25^{\circ} \mathrm{C}$ in $\mathrm{C}$. savignyi), the protein abundance is still higher in C. intestinalis (Fig. 7).

\subsubsection{Extracellular matrix and calcium-binding proteins}

Several components of the extracellular matrix (ECM) showed significant changes in abundance across both species in both experiments (Figs. 2-5, S7). Two ECM proteins, collagen and transglutaminase, are up-regulated in the $22{ }^{\circ} \mathrm{C}$ and $25^{\circ} \mathrm{C}$ treatment groups in HHS C. intestinalis (Fig. S7). In HHS C. savignyi, collagen, fibronectin, and calcium-binding EGF domain, are not up-regulated until $28^{\circ} \mathrm{C}$ (Fig. S7). With collagen expression, we once again see a trend of increased abundance at a lower temperature in $C$. intestinalis when compared to C. savignyi.
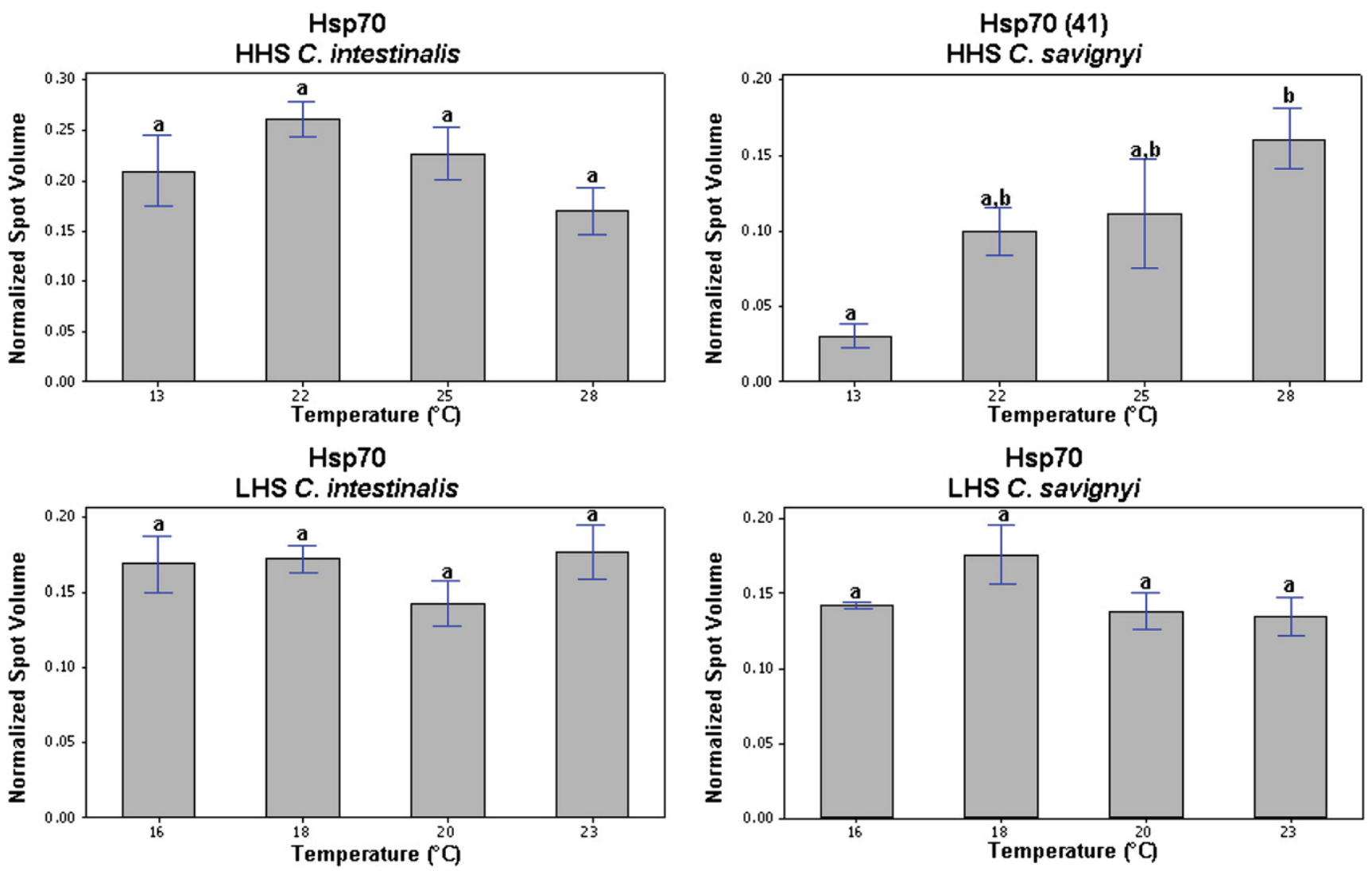

Fig. 6. Expression profile graphs showing the relative expression of one Hsp70 isoform (spot number 41 in HHS C. savignyi) across both species and experiments. Spot numbers are not shown for proteins that do not show significant changes in expression. Spot volumes were obtained by normalizing against the volume of all proteins, and means \pm 1 SEM are shown ( $\mathrm{N}=5$ for all groups, except $13^{\circ} \mathrm{C}$ and $25^{\circ} \mathrm{C}$ in HHS C. savignyi where $\mathrm{N}=4$ ). Treatments with significant differences in expression level are marked with different letters (based on post-hoc Tukey's analysis; $p<0.05$ ). 

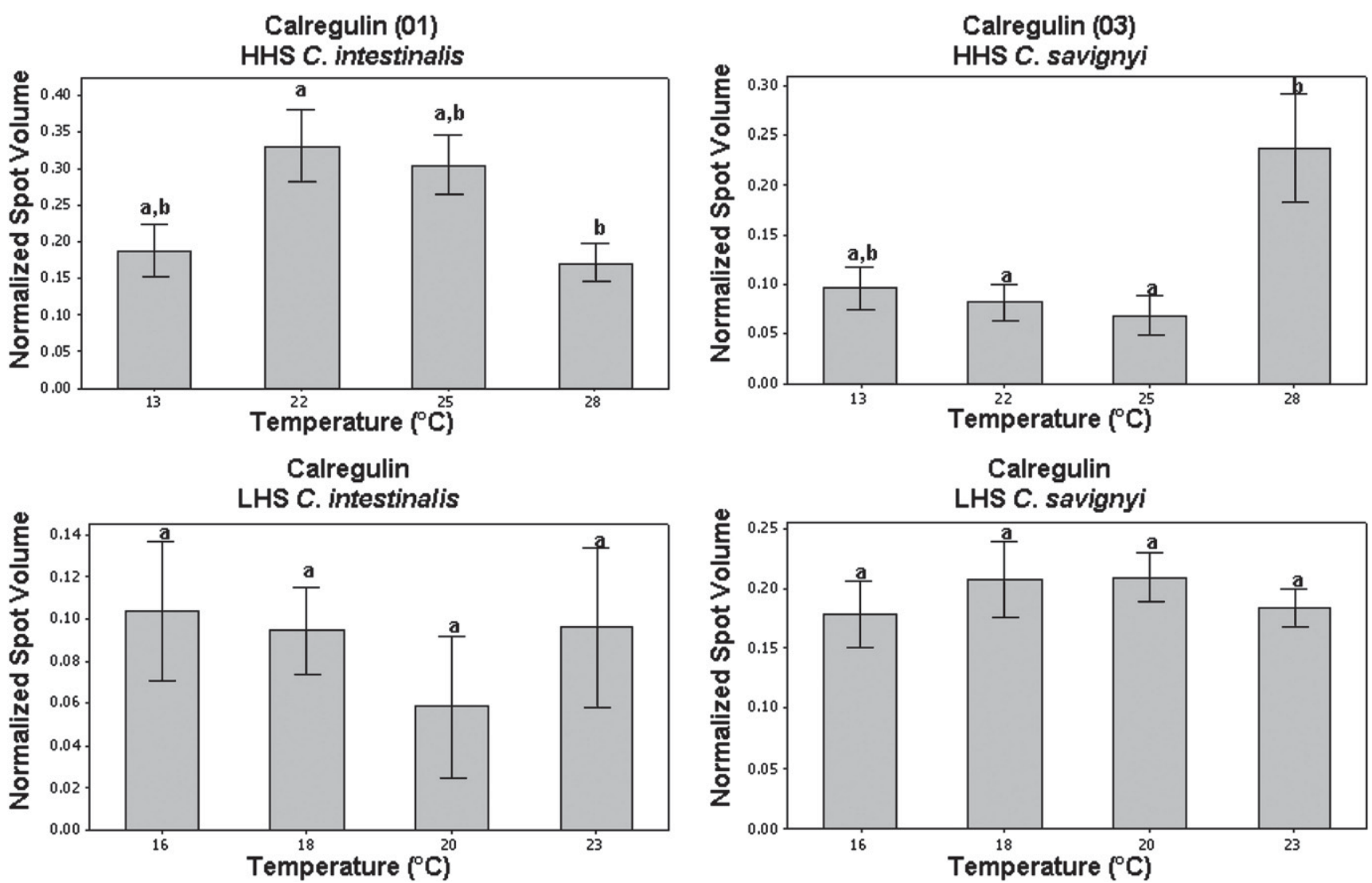

Fig. 7. Expression profile graphs showing the relative expression of one calregulin isoform (spot number 01 in HHS C. intestinalis, and spot number 03 in HHS C. savignyi) across both species and experiments. Spot numbers are not shown for proteins that do not show significant changes in expression. Spot volumes were obtained by normalizing against the volume of all proteins, and means \pm 1 SEM are shown $\left(\mathrm{N}=5\right.$ for all groups, except $13{ }^{\circ} \mathrm{C}$ and $25^{\circ} \mathrm{C}$ in HHS C. savignyi where $\left.\mathrm{N}=4\right)$. Treatments with significant differences in expression level are marked with different letters (based on post-hoc Tukey's analysis; $p<0.05$ ).

Unlike the other significant ECM proteins in HHS C. savignyi, fibrillin2, a glycoprotein made up of multiple calcium-binding EGF domains and responsible for protecting against extracellular proteolysis (Ramirez and Pereira, 1999), shows down-regulation from the control group. In the LHS experiment, $C$. intestinalis shows significant up-regulation of collagen in the $20^{\circ} \mathrm{C}$ treatment, while $C$. savignyi doesn't show significant changes in the expression of collagen (Fig. S7). Instead, fibrinogen $C$, a protein involved in forming fibrin clots and restructuring the ECM in response to tissue damage (Alberts et al., 2008), is up-regulated in the $20^{\circ} \mathrm{C}$ treatment in LHS C. savignyi (Fig. S7).

Another subset of proteins, including calregulin, calcium-vector protein target, and various ECM proteins, were classified based on their ability to bind to calcium. Despite their disparate functions (see Section 4), these proteins were grouped together based on their shared trait of being regulated by calcium (Fig. S8). Interestingly, calcium-binding proteins only show significant expression changes in the HHS experiment, and none were found to change in the LHS experiment.

In HHS C. intestinalis, calregulin is up-regulated in the $22^{\circ} \mathrm{C}$ and $25^{\circ} \mathrm{C}$ treatments, while in HHS C. savignyi, calregulin is not upregulated until the $28{ }^{\circ} \mathrm{C}$ treatment. Calcium-vector protein target, a protein with an unknown function, also shows this trend as one isoform is up-regulated in the $22^{\circ} \mathrm{C}$ and $25^{\circ} \mathrm{C}$ treatments in HHS C. intestinalis, but not until the $28{ }^{\circ} \mathrm{C}$ treatment in C. savignyi. An additional isoform of $\mathrm{Ca}^{2+}$ vector protein target shows up in HHS C. intestinalis, and it is not up-regulated until the $28{ }^{\circ} \mathrm{C}$ treatment. The position of these two isoforms in the HHS C. intestinalis gels show that they have similar molecular masses, but different isoelectric focusing points, which may indicate a post-translational protein modification (Fig. 1). Lastly, some of the significantly changing ECM proteins in
HHS C. intestinalis also bind calcium, including: fibrillin-2, fibronectin, and calcium-binding EGF domain.

\subsubsection{Energy metabolism proteins}

A few proteins involved in energy metabolism show significant changes in their expression across treatments for both species in the HHS experiment, and for C. savignyi in the LHS experiment (Fig. S9). In the HHS experiment, both $C$. intestinalis and $C$. savignyi differentially express ATP synthase F1 $\beta$-subunit, a subunit of the protein embedded in the inner mitochondrial matrix. In $C$. intestinalis, ATP synthase F1 $\beta$-subunit is characterized by up-regulation in the $22{ }^{\circ} \mathrm{C}$ and $25^{\circ} \mathrm{C}$ treatments, while in C. savignyi it is significantly upregulated in the $28{ }^{\circ} \mathrm{C}$ treatment. This constitutes another example of a protein that is up-regulated at a lower temperature in $C$. intestinalis than in $C$. savignyi. ATP synthase F1 $\beta$-subunit also shows up in LHS C. savignyi, where it is up-regulated in the $23^{\circ} \mathrm{C}$ temperature treatment.

A subunit of cytochrome $c$ oxidase, complex IV of the electron transport chain, was found to be significantly up-regulated in the $22{ }^{\circ} \mathrm{C}$ treatment in HHS C. intestinalis. Another mitochondrial protein, malate dehydrogenase (MDH), the enzyme responsible for converting malate into oxaloacetate in the Krebs cycle and also associated with the malate-aspartate shuttle (Minárik et al., 2002), showed differential expression in HHS C. savignyi where it is characterized by significant up-regulation at $28^{\circ} \mathrm{C}$.

Lastly, the glycolytic enzyme glyceraldehyde-3-phosphate dehydrogenase (GAPDH) was differentially expressed in C. savignyi in both the high and low heat stress experiments. In the HHS experiment, GADPH was up-regulated in the $28{ }^{\circ} \mathrm{C}$ treatment group, while in the LHS experiment it was down-regulated at $23^{\circ} \mathrm{C}$. Overall, in the high heat stress experiment, differentially expressed energy metabolism 
proteins are up-regulated at $22^{\circ} \mathrm{C}$ and $25{ }^{\circ} \mathrm{C}$ in C. intestinalis, while they are not up-regulated until $28^{\circ} \mathrm{C}$ in C. savignyi.

\subsubsection{Cytoskeletal elements}

All three major components of the cytoskeleton, intermediate filaments, tubulin monomers, and actin, were found to be differentially expressed in at least one of the heat stress experiments. Intermediate filaments only showed significant changes in abundance in C. savignyi, in both the high and low heat stress experiments. In the HHS experiment, 3 isoforms of intermediate filament A (IF-A) are upregulated in the $25^{\circ} \mathrm{C}$ and $28{ }^{\circ} \mathrm{C}$ temperature treatments, while in the LHS experiment, one IF-A isoform is up-regulated at $23^{\circ} \mathrm{C}$ (Fig. S10).

Both $\alpha$ - and $\beta$-tubulin monomers showed significant changes in their expression in the HHS experiment in both $C$. intestinalis and C. savignyi, while only $\beta$-tubulin monomers were differentially expressed in the LHS experiment, and only in C. intestinalis (Fig. S11). In the HHS experiment, $C$. intestinalis has the same pattern of downregulation in the $28^{\circ} \mathrm{C}$ temperature treatment for both $\alpha$ - and $\beta$-tubulin isoforms. In HHS C. savignyi, two main expression patterns are apparent for the tubulins: one group of $\beta$-tubulin isoforms are characterized by up-regulation in the $28{ }^{\circ} \mathrm{C}$ treatment group, while another group containing five $\alpha$-tubulin and two $\beta$-tubulin isoforms are downregulated in the $25^{\circ} \mathrm{C}$ and $28{ }^{\circ} \mathrm{C}$ treatment groups. These two distinct expression patterns suggest different roles for the $\alpha$ - and $\beta$-tubulin monomers in the C. savignyi cellular response to high heat stress (Fig. S11). In LHS $C$. intestinalis, four $\beta$-tubulin isoforms show significant down-regulation in the $18{ }^{\circ} \mathrm{C}$ and $20^{\circ} \mathrm{C}$ treatments. No $\alpha$-tubulin monomers were identified as being differentially expressed in LHS C. intestinalis, and no tubulin monomers at all were found to have significant expression changes in the C. savignyi LHS experiment.

The last of the three cytoskeletal elements, actin, is differentially expressed for both species in both experiments, and the expression patterns are more diverse than the previously discussed functional categories (Fig. S12). Part of the diversity stems from the fact that actin is one of the most abundant proteins in eukaryotic cells (Schmidt and Hall, 1998), and the number of actin monomers found to be differentially expressed far exceeds any of the other identified proteins.

In HHS C. intestinalis, the expression patterns of actin isoforms and actin-binding proteins can be broken down into two main clusters: the first contains 11 actin isoforms and is characterized by downregulation in the $22{ }^{\circ} \mathrm{C}$ and $25^{\circ} \mathrm{C}$ temperature treatments (Fig. S12). The second cluster contains six actin isoforms, in addition to myosin light chain and two actin-binding proteins, cofilin- 2 and $\alpha$-actinin. This cluster shows significant up-regulation in the $22^{\circ} \mathrm{C}$ and $25^{\circ} \mathrm{C}$ treatment groups (Fig. S12).

In HHS C. savignyi, the multitude of actin isoforms can once again be broken into two clusters (Fig. S12). The first cluster shows upregulation in the $28{ }^{\circ} \mathrm{C}$ treatment, and it contains 17 actin isoforms. The second cluster consists of 16 actin isoforms, which are characterized by down-regulation in the $28{ }^{\circ} \mathrm{C}$ treatment; the exact opposite pattern of the first cluster. No actin-binding proteins showed significant expression changes in HHS C. savignyi.

In the LHS experiment, both species only had a handful of actin isoforms that showed differential expression (Fig. S12). For C. intestinalis, myosin light chain and one muscle actin isoform were up-regulated in the $20^{\circ} \mathrm{C}$ treatment, while the three remaining actin isoforms were upregulated in the $18{ }^{\circ} \mathrm{C}$ temperature group. For C. savignyi, all of the differentially expressed actin isoforms, eight in all, had the same expression pattern of down-regulation from the $16{ }^{\circ} \mathrm{C}$ control.

In summary, in both the high and low heat stress experiments, C. intestinalis shows either up- or down-regulation of actin isoforms at the intermediate temperature treatments, $22^{\circ} \mathrm{C}$ and $25^{\circ} \mathrm{C}$ in the HHS experiment, and $18{ }^{\circ} \mathrm{C}$ and $20^{\circ} \mathrm{C}$ in the LHS experiment. C. savignyi, on the other hand, is characterized by up- or down-regulation actin monomers at the most extreme temperatures, $13^{\circ} \mathrm{C}$ and $28^{\circ} \mathrm{C}$ of the HHS experiment, and $16{ }^{\circ} \mathrm{C}$ and $23^{\circ} \mathrm{C}$ in the LHS experiment.

\subsection{Estimated versus predicted molecular masses}

After identifying the significantly changing proteins for each species in both experiments, a discrepancy was noted between the estimated molecular mass of the identified protein, which is approximated based on the relative position of the protein spot in the gel, and the predicted molecular mass, which is calculated based on the amino acid sequence of the significantly matched protein. For several of the proteins identified, especially in the HHS experiment, the estimated molecular mass is considerably smaller than the molecular mass predicted by the matched amino acid sequence in the genome database, potentially indicating proteolytic degradation of proteins, possibly due to an artifact of sample preparation (Fig. 8).

In order to determine whether species and level of heat stress affect the differences between estimated and predicted molecular mass, a two-factor ANOVA was conducted, revealing a significant effect of heat stress on the difference between estimated and predicted molecular mass $(p=0.024)$. By looking at the raw differences, we were able to assign directionality to the observed differences in molecular mass, and the negative average indicates that the estimated molecular mass values are mostly smaller than the predicted molecular masses. The boxplot shown in Fig. 9 illustrates that, on average, the difference between the estimated and predicted molecular mass is more negative in the HHS experiment than it is in the LHS experiment, indicating that more proteins are degraded in the HHS experiment.

However, some proteins representing distinct functional categories were not equally affected by this breakdown. Actins, tubulins, and ATP synthase F1 $\beta$-subunit seemed to be the most affected across both experiments and species, while the calcium-binding proteins, including calcium-vector protein target, calregulin, and calcium-binding EGF domain, were largely unaffected (Fig. 8). In addition, other proteins including GAPDH, collagen, myosin light chain, and intermediate filaments, also seem to be unaffected.

In order to determine whether the observed differential protein breakdown was an effect of thermal stress, and not merely an artifact of sample preparation, a two-factor ANOVA was conducted comparing the estimated and predicted molecular masses of actin monomers, many of which were identified in all four projects, between species and experiments. This test revealed a significant effect of heat stress level on the amount of breakdown in the actin monomers, with no significant effect of species or interaction between species and heat stress level $(p=0.018)$. This indicates that actin monomers undergo more proteolytic degradation, on average, in the HHS experiment. It is difficult to determine whether the same is true for tubulin monomers and ATP synthase F1 $\beta$-subunits because these proteins were not identified in all four projects and relatively few isoforms were identified overall.

\subsection{Protease inhibitor experiment}

To evaluate the role of protease activity occurring during sample preparation, a third experiment was conducted. Non-heat stressed samples from each species were split into two groups, and were processed with and without compounds known to inhibit the activity of four of the main classes of proteases: cysteine, serine, aspartate, and metalloproteases (Chou and Shen, 2008).

Of the 345 total protein spots in C. intestinalis, 26 (or 8\%) were found to have significant changes in their expression ( $t$-test; $p<0.05$ ), and 17 of these significant spots (65\%) were identified (Fig. S13 and Table S5). As shown in the hierarchical clustering analysis (Fig. S14), some, but not all, of the significantly changing proteins in this experiment overlap with proteins from the heat stress experiments, including ATP synthase F1 $\beta$-subunit, calcium vector protein target, $\alpha$ - and $\beta$-tubulins, along with a few actin isoforms.

For C. savignyi, a total of 315 individual protein spots were detected (Fig. S15). As in C. intestinalis, $8 \%$ of the total (24 spots) showed significant changes in abundance ( $t$-test; $p<0.05$ ), and of these we were 
C. intestinalis HHS Estimated vs. Predicted MM

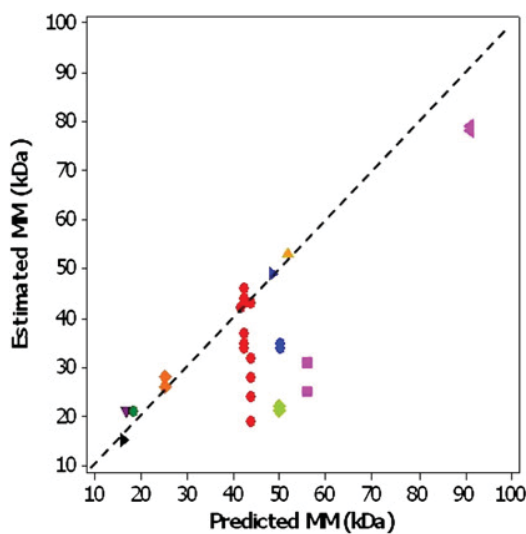

c. intestinalis LHS Estimated vs. Predicted MM

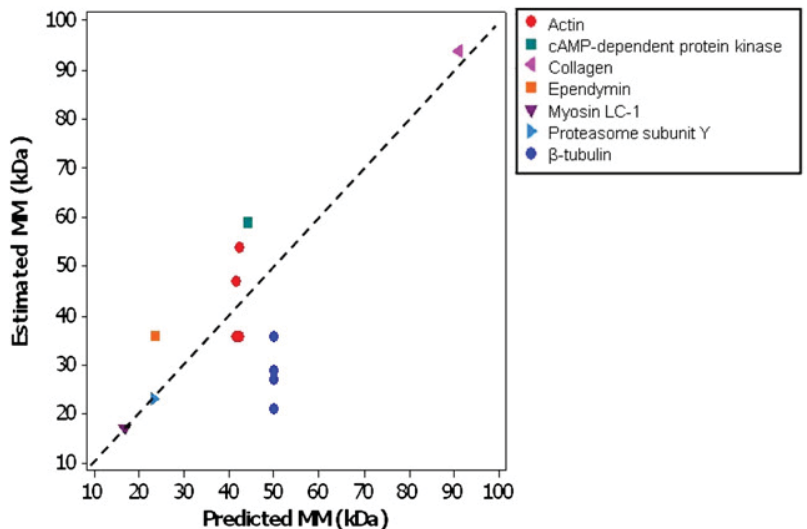

C. savignyi HHS Estimated vs. Predicted MM
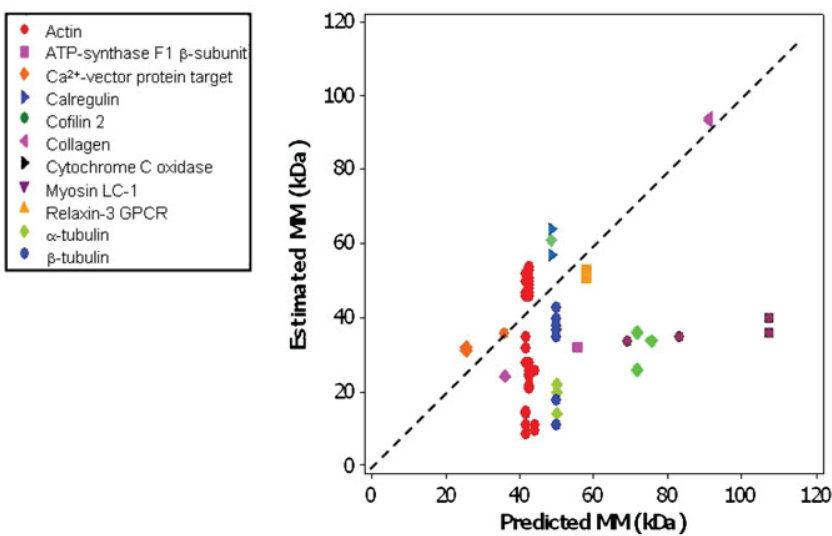

- Actin

ATP-synthase F1 p-subun - $\mathrm{Ca}^{2+}$-binding EGF domain - $\mathrm{C}^{2+}$-vector protein target Calregulin - Collagen - Fibronectin - GADPH - Hsp70 - Hsp9o - Intermediate filament - Mitochondrial MDH - o-tubulin

\section{C. savignyi LHS Estimated vs. Predicted MM}

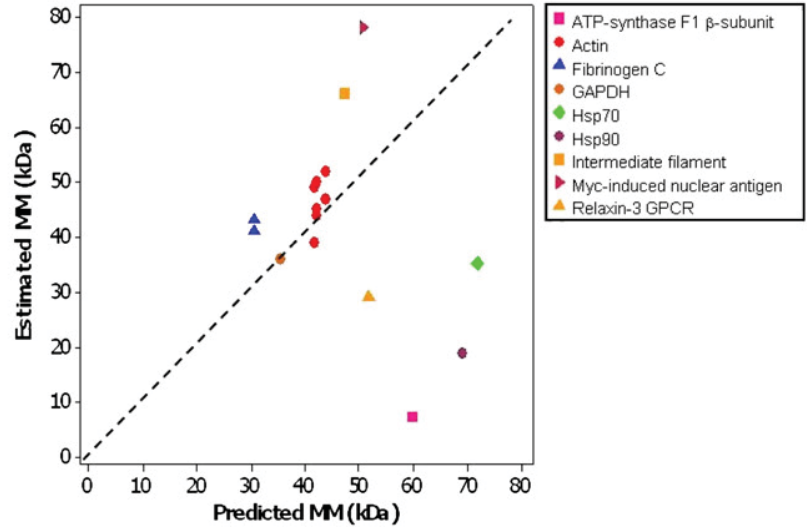

Fig. 8. Scatterplots showing the estimated and predicted molecular mass (MM) of significantly changing proteins identified in both species and experiments. Protein identity is indicated by the shape and color of the data points, as shown in the legends. Dotted lines represent the line $\mathrm{y}=\mathrm{x}$, where the data points should fall if estimated MM is equal to predicted MM. (Note: fibrillin-2 was removed as an outlier from the HHS C. savignyi graph).

able to identify 16 (or 67\%; Fig. S15 and Table S6). Hierarchical clustering again shows an overlap between proteins that change in abundance in response to the use of protease inhibitors and heat stress, namely mitochondrial malate dehydrogenase, calcium vector protein target, intermediate filament, $\beta$-tubulin, and a few actin isoforms (Fig. S16). It is interesting to note that although calcium vector protein target is upregulated in the protease inhibitor treatment, there was no observed

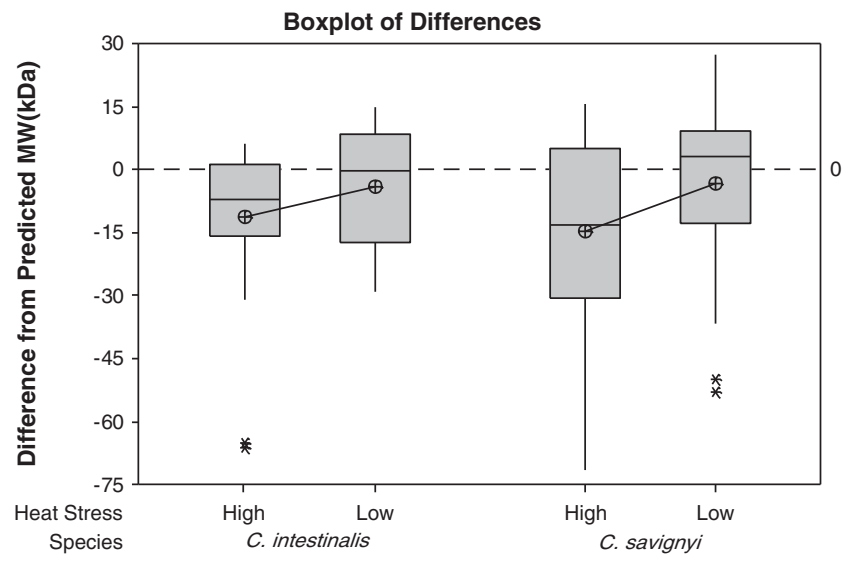

Fig. 9. Boxplot showing the averages of the differences in estimated and predicted molecular mass (MM) across both species and experiments (two-factor ANOVA; $p<0.05$ ). There was a significant effect of heat stress on the average of the differences between estimated and predicted MM. difference between its estimated and predicted molecular masses in any of the experiments.

\section{Discussion}

Few species comparisons of proteomic responses to environmental stress exist to date, especially for the marine environment (for review see Tomanek, 2011). The present study provides a comparison of two sea squirt species that are well-defined in terms of their genome sequences (Dehal et al. 2002; Vinson et al. 2005). They have also served as an ideal study system to learn more about how introduced species impact native communities and about the evolutionary relationships between vertebrates and invertebrates (Corbo et al., 2001; Satoh et al., 2003; McDonald, 2004; Blum et al., 2007). However, very little is known about the congener's tolerance to environmental stresses such as temperature and salinity (Dybern, 1965; Marin et al., 1987; Therriault and Herborg, 2008; Fujikawa et al. 2010). Although several studies define the range of thermal stress that one of the two species experiences, no direct comparisons of the same life stages exists to date. Here we employed a discovery approach, using proteomics to compare the response of $C$. intestinalis and $C$. savignyi to thermal stress.

In a previous study comparing the proteomic stress response in the blue mussel congeners, Mytilus galloprovincialis and M. trossulus, we defined the criteria for comparing proteomes (Tomanek and Zuzow, 2010). In brief, observed changes in protein spot abundance can be due to protein synthesis, degradation, or post-translational modifications, and the term expression is used broadly to describe changes caused by any of these events. Spots that overlap in their position 
within a 2D gel and that were identified as the same protein can be compared directly. Also, conclusions about possible changes in physiological processes, e.g. activation of a metabolic pathway, that are based on several protein identifications are considered more robust than those based on only a single identification.

The results of this study show several distinct expression patterns between the two species. One possible limitation to our interpretation of these results is that because we used the whole organism, we cannot distinguish protein expression differences between tissues. The whole organism was used to overcome the difficulty of separating out a single tissue from Ciona with enough protein for 2D GE. Despite the lack of tissue-specificity, we are still able to compare the distinct species responses to acute thermal stress.

Another difficulty results from the fact that the two heat stress experiments were conducted during different seasons, early spring for the HHS experiment and late summer for the LHS experiment, and thus cannot be directly compared. The seasonal acclimation differences, which are reflected in the two different control temperatures used, may contribute to expression differences at similar temperatures between the two experiments, for example differences between expression at $22{ }^{\circ} \mathrm{C}$ in the HHS experiment and expression at $23^{\circ} \mathrm{C}$ in the LHS experiment. However, by looking at expression patterns within each experiment, and comparing general trends, not specific temperatures, across the two experiments, we are able to indirectly compare the acute responses to extreme and moderate heat stress.

\subsection{Functional expression differences between species and experiments}

By separating expression patterns among proteins by cellular function, we were able to directly compare the cellular processes involved in the response to acute heat stress between the two Ciona congeners. Our results indicate that the two species differ in terms of the temperature at which they increase the expression of molecular chaperones, extracellular matrix proteins, calcium-binding proteins, cytoskeletal elements and proteins involved in energy metabolism. This is especially true in the HHS experiment where C. intestinalis upregulates these proteins at $22^{\circ} \mathrm{C}$ and $25^{\circ} \mathrm{C}$, while $\mathrm{C}$. savignyi only shows increased abundance at $28^{\circ} \mathrm{C}$. For cytoskeletal elements that show changes in expression in both species, tubulins and actin isoforms, C. intestinalis tends to up- or down-regulate these proteins at lower temperatures, $22^{\circ} \mathrm{C} / 25^{\circ} \mathrm{C}$ in HHS and $18{ }^{\circ} \mathrm{C} / 20^{\circ} \mathrm{C}$ in the LHS experiment, while $C$. savignyi shows changes in abundance at the highest exposure temperatures, $28{ }^{\circ} \mathrm{C}$ in HHS and $23^{\circ} \mathrm{C}$ in LHS. Intermediate filaments only showed changes in abundance in $C$. savignyi, although they follow the pattern of up-regulation at the highest treatment temperatures, $28^{\circ} \mathrm{C}$ in HHS and $23^{\circ} \mathrm{C}$ in LHS. These expression differences between the two species span a wide-range of functional categories and suggest that $C$. intestinalis responds to acute heat shock at a lower temperature than $C$. savignyi. In addition, expression of specific isoforms of the molecular chaperones Hsp70 and calregulin show that in the HHS experiment, $C$. intestinalis starts out with higher baseline levels than $C$. savignyi, and even after up-regulation, these proteins are still more abundant in C. intestinalis.

Another interesting difference in protein expression was observed between the HHS and LHS experiments. In both species, calciumbinding proteins only show significant changes in expression under HHS conditions. This may indicate that intense thermal stress, above $23^{\circ} \mathrm{C}$, triggers calcium-signaling cascades. Calcium signaling is an important mechanism for regulating several molecular pathways and cellular processes, including cell proliferation, excitability, exocytosis, and transcription (Berridge et al., 2003; Clapham, 2007). Calcium has also been shown to play an important role in mitochondrial dysfunction, where a calcium overload can increase the number of reactive oxygen species generated during cellular respiration, and trigger cytochrome $c$-mediated apoptosis (Brookes et al., 2004). Even though we cannot pinpoint the specific role of calcium in the acute heat stress response of the Ciona congeners, the appearance of several calciumbinding proteins in the HHS experiment only indicates that calciumsignaling is one mechanism that is sensitive to thermal fluctuations and may be involved in dealing with extreme thermal stress.

It is remarkable that Ciona does not detectably express several proteins that are typically induced in response to acute heat stress, e.g. small Hsps. In addition, the Hsps that we did identify, Hsp70 and Hsp90, were up-regulated in C. savignyi at the highest temperature $\left(28^{\circ} \mathrm{C}\right)$ only and differed in their estimated mass from the predicted (Table S2 and S4). These isoforms were also expressed at control temperatures, and neither one was affected by the protease inhibitor treatment (Figs S14 and S16). One possible explanation is that we did not inhibit all proteases, neither with our standard homogenization buffer nor with our protease-inhibitor-'spiked' buffer. Another nonexclusive possibility is that there is a 'catastrophic' thermal breakdown of proteins at $28^{\circ} \mathrm{C}$ in $\mathrm{C}$. savignyi that even leads to the proteolytic breakdown of Hsp70. Alternatively, we may have misidentified an Hsp40-family member as an Hsp70, although the number of matched peptides, ranging from two to seven, speaks against this possibility (Tables S2 and S4). Previous studies using 2D GE showed evidence for the self-degradation of Hsp70 during recovery from heat stress, possibly as a quick-turnover mechanism to prevent the chaperoning function of Hsp70 from interfering with intact proteins (Mitchell et al., 1985; Cluss et al., 1996).

\subsection{Species-specific differences in thermal sensitivities}

When comparing the number of significantly changing protein isoforms between the HHS and LHS experiments, which differ in both temperature range and control temperature, it is obvious that for both species a greater number of proteins change in the HHS experiment. For C. intestinalis, 51 protein spots changed significantly in HHS versus 20 under LHS conditions, and for C. savignyi, 74 spots changed in HHS versus only 17 spots in the LHS experiment. Many of these additional protein isoforms were found to have a lower molecular mass than was predicted based on their matched amino acid sequence, suggesting some degree of proteolytic degradation, which was most likely enhanced by the unfolding of proteins at the extreme treatment temperatures used in the HHS experiment.

Importantly, the comparison of two different species at two different thermal ranges shows statistical evidence for a tiered response of protein degradation to heat stress (Fig. 9). The fact that the direction and magnitude of the differences between estimated and predicted molecular mass vary across temperature experiments indicates that the observed proteolytic breakdown is in part due to thermal stress. If the degradation was due solely to an artifact of sample preparation, the average differences between the estimated and predicted molecular mass should not show significant differences across experiments (Fig. 9).

Additionally, certain classes of proteins represented by our 2D gels, namely actins, tubulins, and ATP synthase F1 $\beta$-subunit isoforms, were more affected by proteolytic degradation across both experiments (Fig. 8). Actin monomers in particular showed significantly more proteolytic breakdown under HHS conditions when compared to the amount of breakdown observed in the LHS experiment $(p=0.018)$. This indicates that these particular proteins are more sensitive to breakdown in response to thermal stress.

Further proof that the observed proteolytic degradation is not solely an artifact of sample preparation comes from the experiment we conducted to compare protein expression differences in response to protease inhibitors. Although some of the significantly changing proteins identified in this experiment overlapped with proteins found in the heat stress experiments, far fewer proteins were detected overall, including limited numbers of actin and tubulin isoforms, and only one or two proteins involved in energy metabolism and calcium-binding. It is worth noting that the identified calcium-binding proteins, calcium 
vector protein target isoforms, showed no differences between their estimated and predicted molecular masses, suggesting that they were not affected by the proteolytic activity that affected other functional categories. This indicates that the intact calcium-binding proteins identified in the protease inhibitor experiment are not showing significant changes in expression because of proteolytic breakdown that occurred during sample preparation, but are instead playing a role in the cellular response to the protease inhibitor treatment.

Several studies used proteomic techniques to obtain a global perspective of proteins that are intrinsically disordered (Csizmók et al., 2006), hyperstable (Prosinecki et al., 2006), or resistant to proteolysis (Park et al., 2007). None so far has used the discrepancy between estimated and predicted molecular mass as an indication of the differential thermal sensitivities of proteins in vivo during heat stress. From our results it appears as if actin, tubulin and ATP synthase F $1 \beta$-subunit are the most thermally unstable proteins of those that we were able to detect in our gels (Fig. 8). In the case of actin we know that its thermal stability (and to some degree unfolding) depends on a number of actinbinding proteins, nucleotides such as ATP (Levitsky et al., 2008), and possibly interactions with membrane lipids (Gicquaud, 1993). In stressful conditions, reduced levels of available ATP, either due to decreased production or increased cellular demand, may lead to greater unfolding of actin and result in a greater susceptibility to proteolytic breakdown. At the same time, a number of denaturing proteins also compete for the assistance of chaperonins during heat stress, possibly resulting in an insufficient re-folding response for actin, and an overall breakdown of actin monomers and polymers. Cytoskeletal elements are also known to be stabilized by small heat-shock proteins that prevent the aggregation of thermally denatured actin (Levitsky et al., 2008). Another possibility is that actin and tubulin may simply be the most proteolytically susceptible proteins under heat stress because of their high abundance, although other highly abundant proteins do not show similar trends, e.g. calregulin. Although more work must be done to validate these conclusions regarding the increased susceptibility of cytoskeletal proteins to thermal breakdown, the application of electrophoresis-based proteomics may provide an ideal approach to assess protein thermal stabilities indirectly under in vivo conditions.

\subsection{Species-specific strategies to respond to environmental stress}

In order to fully understand the responses of organisms to thermal stress and the resulting ecological consequences, we must integrate the study of molecular and cellular physiology with the study of wholeorganism and population-level responses (Pörtner et al., 2006). Therefore, it is important to attempt to link the observed molecular mechanisms driving the cellular stress response with their larger ecological implications. Overall, the species-specific differences in thermal stress response suggest that $C$. intestinalis responds more quickly to thermal stress and by doing so prevents further damage. The fact that it has higher steady-state levels of molecular chaperones may support this interpretation of a readiness to respond to stressful conditions. In comparison, C.savignyi's expression profiles suggest a delayed response and thus widespread unfolding of proteins at the highest level of thermal stress, with enhanced proteolytic breakdown as a consequence. Lower steady-state levels of some chaperones may serve as an indication that C. savignyi lacks the ability to quickly respond to stressful conditions. Overall, the species-specific differences, namely $C$. intestinalis's early responsiveness to thermal stress and higher steady-state levels of molecular chaperones, suggest higher thermal tolerance, which may explain the wider distribution range observed for C. intestinalis.

Studies of congeneric marine snail species (genus Tegula) have illustrated the importance of timing when comparing the heat shock responses of closely related species (Tomanek and Somero, 2000). The present study was limited to characterizing the stress response at a single time point, $16 \mathrm{~h}$ after exposure to thermal stress, and therefore may be missing key elements of the stress response and the species- specific differences. Future studies should follow the time course of the Ciona stress response over an extended period to assess species differences.

\section{Conclusions}

The present study raises a number of questions. First, is it possible to compare protein thermal stabilities using the experimental design that we applied in the HHS experiment? Yes, it seems so, and this approach could also make it possible to obtain global comparisons of protein thermal stabilities among differently adapted species and populations. This will provide important insights into the "weak" links in molecular architecture that will set the thermal constraints for organisms faced with future temperature increases due to climate change. Second, if actin and tubulin are among the most thermally susceptible proteins, the question is why? Asking this question may lead us to focus on cellular factors that control thermal stability under in vivo conditions, such as cellular energy status in form of ATP.

Ciona poses some special challenges to conducting proteomics experiments. We had to use the whole animal with the tunic removed to obtain sufficient amounts of protein for 2D GE. More targeted approaches, such as focusing on a single tissue, or additional enrichment strategies may be required to discover changes in lower abundance proteins. Studies examining the effects of thermal stress on respiration or heart rates of the two Ciona congeners are still scant or absent and would be insightful in supporting our conclusions based on work at the molecular level.

Overall, the current study offers a potential approach into how we can conduct a global comparison of protein thermal stabilities and thus of the molecular perturbations that are thought responsible for the activation of the cellular stress response (Kültz, 2005).

\section{Acknowledgements}

We thank several members of the Tomanek laboratory, specifically Sarah Johnson, James Koman, Dr. Jennifer Oquendo and Marcus Zuzow, for their help and assistance during various phases of the project. The work was supported with funding from the National Science Foundation grant to L. T. (IOS-0717087) and the California Central Coast Research Partnership (to L. T.), which is administered through California Polytechnic State University, San Luis Obispo.

\section{References}

Alberts, B., Johnson, A., Lewis, J., Raff, M., Roberts, K., Walter, P., 2008. Internal organization of the cell. In: Anderson, M., Granum, S. (Eds.), The Molecular Biology of the Cell. Garland Science. Taylor \& Francis Group, LLC, New York, NY, USA, pp. 617-1115.

Berná, L., Alvarez-Valin, F., D'Onofrio, G.D., 2009. How fast is the sessile Ciona? Comp. Funct. Genomics. doi:10.1155/2009/875901.

Berridge, M.J., Bootman, M.D., Roderick, H.L., 2003. Calcium signaling: dynamics, homeostasis, and remodeling. Nat. Rev. Mol. Cell Biol. 4, 517-529.

Berth, M., Moser, F.M., Kolbe, M., Bernhardt, J., 2007. The state of the art in the analysis of two-dimensional gel electrophoresis images. Appl. Microbiol. Biotechnol. 76, 1223-1243.

Blum, J.C., Chang, A.L., Liljesthröm, M., Schenk, M.E., Steinberg, M.K., Ruiz, G.M., 2007. The non-native solitary ascidian Ciona intestinalis (L.) depresses species richness. J. Exp. Mar. Biol. Ecol. 342, 5-14.

Brookes, P.S., Yoon, Y., Robotham, J.L., Anders, M.W., Sheu, S.-S., 2004. Calcium, ATP, and ROS: a mitochondrial love-hate triangle. Am. J. Physiol. Cell Physiol. 287, C817-C833.

Buckley, B.A., Gracey, A.Y., Somero, G.N., 2006. The cellular response to heat stress in the goby Gillichthys mirabilis: a cDNA microarray and protein-level analysis. J. Exp. Biol. 209, 2660-2677. 
Byrd, J., Lambert, C.C., 2000. Mechanism of the block to hybridization and selfing between the sympatric ascidians Ciona intestinalis and Ciona savignyi. Mol. Reprod. Dev. 55, 109-116.

Chou, K.-C., Shen, H.-B., 2008. ProtIdent: a web server for identifying proteases and their types by fusing functional domain and sequential evolution information. Biochem. Biophys. Res. Commun. 376, 321-325.

Clapham, D.E., 2007. Calcium signaling. Cell 131, 1047-1058.

Cluss, R.G., Goel, A.S., Rehm, H.L., Schoenecker, J.G., Boothby, J.T., 1996. Coordinate synthesis and turnover of heat shock proteins in Borrelia burgdorferi: degradation of DnaK during recovery from heat shock. Infect. Immun. 64, 1736-1743.

Corbo, J.C., DiGregorio, A., Levine, M., 2001. The ascidian as a model organism in developmental biology. Cell 106, 535-538.

Csizmók, V., Szöllösi, Friedrich, P., Tompa, P., 2006. A novel two-dimensional electrophoresis technique for the identification of intrinsically unstructured proteins. Mol. Cell. Proteomics 5, 265-273.

Dehal, P., Satou, Y., Campbell, R.K., Chapman, J., Degnan, J., DeTomaso, A., Davidson, B., DiGregorio, A., Gelpke, M., Goodstein, D.M., Harafuji, N., Hastings, K.E.M., Ho, I., Hotta, K., Huang, W., Kawashima, T., Lemaire, P., Martinez, D., Meinertzhagen, I.A., necula, S., Nonaka, M., Terry, A., Yamada, L., Wang, H.G., Awazu, S., Azumi, K., Boore, J., Branno, M., Chin-bow, S., DeSantis, R., Doyle, S., Francino, P., Keys, D.N., Haga, S. Hayashi, H., Hino, K., Imai, K.S., Inaba, K., Kano, S., Kobayashi, K., Kobayashi, M., Lee, B.I., Makabe, K.W., Manohar, C., Matassi, G., Medina, M., Mochizuki, Y., Mount, S., Morishita, T., Miura, S., Nakayama, A., Nishizaka, S., Nomoto, H., Ohta, F., Oishi, K., Rigoutsos, I., Sano, M., Sasaki, A., Sasakura, Y., Shoguchi, E., Shin-I, T., Spagnuolo, A., Stainier, D., Suzuki, M.M., Tassy, O., Takatori, N., Tokuoka, M., Yagi, K., Yoshizaki, F., Wada, S., Zhange, C., Hyatt, P.D., Larimer, F., Detter, C., Doggett, N., Glavina, T., Hawkins, T., Richardson, P., Lucas, S., Kohara, Y., Levine, M., Satoh, N., Rokhsar, D.S. 2002. The draft genome of Ciona intestinalis: insights into chordate and vertebrate origins. Science 298, 2157-2167.

Dybern, B.I., 1965. The life cycle of Ciona intestinalis (L.) f. typica in relation to the environmental temperature. Oikos 16, 109-131.

Feder, M.E., Walser, J.C., 2005. The biological limitations of transcriptomics in elucidating stress and stress responses. J. Evol. Biol. 18, 901-910.

Fujikawa, T., Munakata, T., Kondo, S.-I., Satoh, N., Wada, S., 2010. Stress response in the ascidian Ciona intestinalis: transcriptional profiling of genes for the heat shock protein 70 chaperone system under heat stress and endoplasmic reticulum stress. Cell Stress Chaperones 15, 193-204.

Garbuz, D., Evgenev, M.B., Feder, M.E., Zatsepina, O.G., 2003. Evolution of thermotolerance and the heat-shock response: evidence from inter/intraspecific comparison and interspecific hybridization in the virilis species group of Drosophila I. Thermal phenotype. J. Exp. Biol. 206, 2399-2408.

Gicquaud, C., 1993. Actin conformation is drastically altered by direct interaction with membrane lipids: a differential scanning calorimetry study. Biochemistry 32, 11873-11877.

Gracey, A.Y., Cossins, A.R., 2003. Application of microarray technology in environmental and comparative physiology. Annu. Rev. Physiol. 65, 231-259.

Gracey, A.Y., Chaney, M.L., Boomhower, J.P., Tyburczy, W.R., Connor, K., Somero, G.N. 2008. Rhythms of gene expression in a fluctuating intertidal environment. Curr. Biol. 18, 1501-1507.

Herdman, W.A., 1882. Report on the Tunicata collected during the voyage of H.M.S Challenger during the years 1873-76. Pt. I, Ascidiae simplices. Zool. Chall. Exped. 6 (17), 1-296.

Hewitt, C.L., Martin, R.B., Sliwa, C., McEnnulty, F.R., Murphy, N.E., Jones, T., Cooper, S. 2002. Ciona intestinalis species summary. National Introduced Marine Pest Information System (NIMPIS)Web publication http://crimp.marine.csiro.au/ nimpis2002Date of access: 5/31/2009.

Hochachka, P.W., Somero, G.N., 2002. Temperature. Biochemical Adaptation: Mechanism and Process in Physiological Evolution. Oxford University Press, New York, NY, USA, pp. 290-449.

Hoshino, Z., Tokioka, T., 1967. An unusually robust Ciona from the Northeastern coast of Honshu Island, Japan. Publ. Seto. Mar. Biol. Lab. 15, 275-290.

Ibarz, A., Martin-Perez, M., Blasco, J., Bellido, D., de Oliveira, E., Fernandez-Borras, J., 2010. Gilthead sea bream liver proteome altered at low temperatures by oxidative stress. Proteomics 10, 963-975.

IPCC, 2007. Fourth assessment report: climate change 2007. The Physical Science Basis. Cambridge University Press, Cambridge.

Kültz, D., 1996. Plasticity and stressor specificity of osmotic and heat shock response of Gillichthys mirabilis gill cells. Am. J. Physiol. 271, C1181-C1193.

Kültz, D., 2005. Molecular and evolutionary basis of the cellular stress response. Annu. Rev. Physiol. 67, 225-257.

Lambert, G., 2003. New records of ascidians from the NE Pacific: a new species of Trididemnum, range extension and redescription of Aplidiopsis pannosum (Ritter, 1899 ) including its larva, and several non-indigenous species. Zoosystema 25 665-679.

Levitsky, D.I., Pivovarova, A.V., Mikhailova, V.V., Nikolaeva, O.P., 2008. Thermal unfolding and aggregation of actin stabilization and destabilization of actin filaments. FEBS J. 275, 4280-4295.

Linnaeus, C., 1767. Systema naturae, Tom. I. Pars II. Editio duodecima, reformata Holmiae. (Laurentii Salvii), pp. 533-1327.

Lockwood, B.L., Sanders, J.G., Somero, G.N., 2010. Transcriptomic responses to heat stress in invasive and native blue mussels (genus Mytilus): molecular correlates of invasive success. J. Exp. Biol. 213, 3559-3574.
Marin, M.G., Bressan, M., Beghi, L., Brunetti, R., 1987. Thermo-haline tolerance of Ciona intestinalis (L., 1767) at different developmental stages. Cah. Biol. Mar. 28, 47-57.

McDonald, J., 2004. The invasive pest species Ciona intestinalis (Linnaeus, 1767) reported in a harbour in southern Western Australia. Mar. Pollut. Bull. 49, 854-874.

Millar, R.H., 1953. Ciona. L.M.B.C. Memoirs XXXV. Liverpool University Press, Liverpool.

Millar, R.H., 1971. The biology of ascidians. Adv. Mar. Biol. 9, 1-100.

Minárik, P., Tomášková, N., Kollárová, M., Antalík, M., 2002. Malate dehydrogenases structure and function. Gen. Physiol. Biophys. 21, 257-265.

Mitchell, H.K., Petersen, N.S., Buzin, C.H., 1985. Self-degradation of heat shock proteins. Proc. Natl. Acad. Sci. USA 82, 4969-4973.

Nash, P.D., Opas, M., Michalak, M., 1994. Calreticulin: not just another calcium-binding protein. Mol. Cell. Biochem. 135, 71-78.

Nomaguchi, T.A., Nishijima, C., Minowa, S., Hashimoto, M., Haraguchi, C., Amemiya, S., Fujisawa, H., 1997. Embryonic thermosensitivity of the ascidian, Ciona savignyi. Zool. Sci. 14, 511-515.

Nydam, M.L., Harrison, R.G., 2007. Genealogical relationships within and among shallow-water Ciona species (Ascidiacea). Mar. Biol. 151, 1839-1847.

Park, C., Zhou, S., Gilmore, J., Marqusee, S., 2007. Energetics-based protein profiling on a proteomic scale: identification of proteins resistant to proteolysis. J. Mol. Biol. 368 , $1426-1437$.

Petersen, J.K., Riisgård, H.U., 1992. Filtration capacity of the ascidian Ciona intestinalis and its grazing impact in a shallow fjord. Mar. Ecol. Prog. Ser. 88, 9-17.

Podrabsky, J.E., Somero, G.N., 2004. Changes in gene expression associated with acclimation to constant temperature and fluctuating daily temperatures in an annual killifish Austrofundulus limnaeus. J. Exp. Biol. 207, 2237-2254.

Pörtner, H.O., 2010. Oxygen- and capacity-limitation of thermal tolerance: a matrix for integrating climate-related stressor effects in marine ecosystems. J. Exp. Biol. 213, 881-893.

Pörtner, H.O., Bennet, A.F., Bozinovic, F., Clarke, A., Lardies, M.A., Lucassen, M., Pelster, B., Schiemer, F., Stillman, J.H., 2006. Trade-offs in thermal adaptation: the need for a molecular to ecological integration. Physiol. Biochem. Zool. 79, 295-313.

Prosinecki, V., Bothelo, H.M., Francese, S., Mastrobuoni, G., Moneti, G., Urich, T., Kletzin, A., Gomes, C.M., 2006. A proteomic approach toward the selection of proteins with enhanced intrinsic conformational stability. J. Proteome Res. 5, 2720-2726.

Ramirez, F., Pereira, L. 1999. The fibrillins. Int. J. Biochem. Cell Biol. 31, 255-259.

Ritter, W.E., Forsyth, R.A., 1917. Ascidians of the littoral zone of southern California. Univ. Calif. Publ. Zool. 16, 439-512.

Sanders, B.M., Hope, C., Pascoe, V.M., Martin, L.S., 1991. Characterization of stress protein response in two species of Colisella limpets with different temperature tolerances. Physiol. Zool. 64, 1471-1489.

Satoh, N., Satou, Y., Davidson, B., Levine, M., 2003. Ciona intestinalis: an emerging model for whole-genome analyses. Trends Genet. 19, 376-381.

Schmidt, A., Hall, M.N., 1998. Signaling to the actin cytoskeleton. Annu. Rev. Cell. Dev. Biol. 14, 305-338.

Small, K.S., Brudno, M., Hill, M.M., Sidow, A., 2007. A haplome alignment and reference sequence of the highly polymorphic Ciona savignyi genome. Genome Biol. 8 R41.1-R41.14.

Somero, G.N., 2010. The physiology of climate change: how potentials for acclimatization and genetic adaptation will determine 'winners' and 'losers'. J. Exp. Biol. 213, 912-920.

Stillman, J.H., Tagmount, A., 2009. Seasonal and latitudinal acclimatization of cardiac transcriptome responses to thermal stress in porcelain crabs, Petrolisthes cinctipes. Mol. Ecol. 18, 4206-4226.

Svane, I., Havenhand, J.N., 1993. Spawning and dispersal in Ciona intestinalis (L.). Mar. Ecol. 14, 53-66.

Therriault, T.W., Herborg, L.-M., 2008. Predicting the potential distribution of the vase tunicate Ciona intestinalis in Canadian waters: informing a risk assessment. ICES J. Mar. Sci. 65, 788-794

Tomanek, L., 2005. Two-dimensional gel analysis of the heat-shock response in marine snails (genus Tegula): interspecific variation in protein expression and acclimation ability. J. Exp. Biol. 208, 3133-3143.

Tomanek, L., 2008. The importance of physiological limits in determining biogeographical range shifts due to global climate change: the heat-shock response. Physiol. Biochem. Zool. 81, 709-717.

Tomanek, L., 2010. Variation in the heat shock response and its implication for predicting the effect of global climate change on species' biogeographical distribution ranges and metabolic costs. J. Exp. Biol. 213, 971-979.

Tomanek, L., 2011. Environmental proteomics: changes in the proteome of marine organisms in response to environmental stress, pollutants, infection, symbiosis, and development. Annu. Rev. Mar. Sci. 3, 373-399.

Tomanek, L., Somero, G.N., 2000. Time course and magnitude of synthesis of heat-shock proteins in congeneric marine snails (genus Tegula) from different tidal heights. Physiol. Biochem. Zool. 73, 249-256.

Tomanek, L.,Zuzow, M.J.,2010. The proteomic response of the mussel congeners Mytilus galloprovincialis and $M$. trossulus to acute heat stress: implications for thermal tolerance limits and metabolic costs of thermal stress. J. Exp. Biol. 213, 3559-3574.

Vinson, J.P., Jaffe, D.B., O'Neill, K.O., Karlsson, E.K., Stange-Thomann, N., Anderson, S. Mesirov, J.P., Satoh, N., Satou, Y., Nusbaum, C., Birren, B., Galahan, J.E., Lander, E.S., 2005. Assembly of polymorphic genomes: algorithms and application to Ciona savignyi. Genome Res. 15, 1127-1135.

White, C.N., Hightower, L.E., Schultz, R.J., 1994. Variation in heat-shock proteins among species of desert fishes (Poeciliidae, Poeciliopsis) Mol. Biol. Evol. 11, 106-119. 